Portland State University

PDXScholar

\title{
Balanced Polymorphism Fuels Rapid Selection in an Invasive Crab Despite High Gene Flow and Low Genetic Diversity.
}

\author{
C K. Tepolt \\ Woods Hole Oceanographic Institution \\ E D. Grosholz \\ DepUniversity of California, Davis \\ Catherine E. de Rivera \\ Portland State University \\ G M. Ruiz \\ Smithsonian Environmental Research Center, Smithsonian Institution
}

Follow this and additional works at: https://pdxscholar.library.pdx.edu/esm_fac

Part of the Environmental Sciences Commons

Let us know how access to this document benefits you.

\section{Citation Details}

Tepolt, C. K., Grosholz, E. D., de Rivera, C. E., \& Ruiz, G. M. (2021). Balanced polymorphism fuels rapid selection in an invasive crab despite high gene flow and low genetic diversity. Molecular Ecology, mec.16143. https://doi.org/10.1111/mec.16143

This Post-Print is brought to you for free and open access. It has been accepted for inclusion in Environmental Science and Management Faculty Publications and Presentations by an authorized administrator of PDXScholar. Please contact us if we can make this document more accessible: pdxscholar@pdx.edu. 
2 DR. CAROLYN TEPOLT (Orcid ID : 0000-0002-7062-3452)

3

4

5 Article type : Original Article

6

7

8

Balanced polymorphism fuels rapid selection in an invasive crab despite high gene flow and low genetic diversity

10

CK Tepolt ${ }^{1, *}$, ED Grosholz², CE de Rivera ${ }^{3}$, GM Ruiz $^{4}$

12

13 'Department of Biology, Woods Hole Oceanographic Institution, 266 Woods Hole Road,

14 Woods Hole, MA 02543

15 2Department of Environmental Science and Policy, University of California, Davis, CA 95616

16 3Department of Environmental Science and Management, Portland State University, Box 751,

17 Portland, OR 97207

$18{ }^{4}$ Smithsonian Environmental Research Center, Smithsonian Institution, 647 Contees Wharf

19 Road, Edgewater, MD 21037

20

$21{ }^{*}$ Corresponding Author:

22 Carolyn Tepolt

23 Department of Biology

24 Woods Hole Oceanographic Institution

25266 Woods Hole Road, MS \#33

26 508-289-3357

27 ctepolt@whoi.edu

30 Keywords: rapid adaptation, invasive species, island of divergence, seascape genomics, This article has been accepted for publication and undergone full peer review but has not been through the copyediting, typesetting, pagination and proofreading process, which may lead to differences between this version and the Version of Record. Please cite this article as doi: 10.1111/MEC.16143

This article is protected by copyright. All rights reserved 


\section{Abstract:}

34 Adaptation across environmental gradients has been demonstrated in numerous systems with 35 extensive dispersal, despite high gene flow and consequently low genetic structure. The 36 speed and mechanisms by which such adaptation occurs remain poorly resolved, but are 37 critical to understanding species spread and persistence in a changing world. Here, we 38 investigate these mechanisms in the European green crab Carcinus maenas, a globally 39 distributed invader. We focus on a northwestern Pacific population that spread across $>12$ 40 degrees of latitude in 10 years from a single source, following its introduction <35 years ago. 41 Using six locations spanning $>1,500 \mathrm{~km}$, we examine genetic structure using 9,376 Single 42 Nucleotide Polymorphisms (SNPs). We find high connectivity among five locations, with 43 significant structure between these locations and an enclosed lagoon with limited connectivity 44 to the coast. Among the five highly connected locations, the only structure observed was a 45 cline driven by a handful of SNPs strongly associated with latitude and winter temperature.

46 These SNPs are almost exclusively found in a large cluster of genes in strong linkage 47 disequilibrium that was previously identified as a candidate for cold tolerance adaptation in 48 this species. This region may represent a balanced polymorphism that evolved to promote 49 rapid adaptation in variable environments despite high gene flow, and which now contributes 50 to successful invasion and spread in a novel environment. This research suggests an answer 51 to the paradox of genetically depauperate yet successful invaders: populations may be able to 52 adapt via a few variants of large effect despite low overall diversity. 


\section{Introduction}

55 In the ocean, where many species are characterized by large population sizes, long-distance 56 planktonic dispersal, and broad ranges (Kinlan \& Gaines, 2003; Palumbi \& Pinsky, 2014),

57 there has been a classical assumption of genetic homogeneity and little persistent 58 differentiation (Hedgecock, 1986). Recently, however, both population genomics and 59 comparative physiology have uncovered evidence of genetic selection and functional 60 differences among widespread populations living across varied marine environments (Sanford 61 \& Kelly, 2011; Pespeni \& Palumbi, 2013). Likewise, genetic studies and associated modeling 62 have detected subtle genetic structure driven by oceanography in species that disperse 63 widely (Galindo, Olson, \& Palumbi, 2006; White et al., 2010; Xuereb et al., 2018). This 64 increasing evidence for differentiation in the sea begs the question of how quickly, and through which mechanisms, marine species may cope with rapidly changing environmental 66 conditions (Munday, Warner, Monro, Pandolfi, \& Marshall, 2013). Introduced species, which

67 in many cases establish and thrive in novel habitats, offer the opportunity to examine these 68 questions in the context of the natural environment (Blackburn, 2008; Lee, Kiergaard, 69 Gelembiuk, Eads, \& Posavi, 2011).

71 Marine species exhibit a spectrum of evolutionary mechanisms based in part on their 72 dispersal. Local adaptation in the classical sense is restricted to species with relatively limited 73 dispersal, which facilitates the selection and retention of adaptive alleles within a population 74 (Kawecki \& Ebert, 2004). Relatively isolated populations are also likely to diverge due to

neutral processes, as genetic drift changes allele frequencies across the genome (Ellingson \& Krug, 2016; Prunier, Dubut, Chikhi, \& Blanchet, 2017). On the other end of this evolutionary spectrum lie open marine systems, where alleles are continually exported from each location to a mixed pool of larvae that may settle in environments far different from their sources. In this dynamic, balanced polymorphism is favored, and adaptive variation is maintained within the population as a whole (Sanford \& Kelly, 2011). These adaptive alleles mix as larvae disperse, and the environmental conditions they encounter as they recruit can result in strong and rapid selection that culls less-fit alleles from the local population (Sotka, 2012). This phenomenon has been described largely in the context of maintaining differentiation across 
84 small-scale environmental differences year after year in systems where the scale of dispersal

85 far exceeds the scale of selection. For example, strong selection to salinity appears to have 86 maintained an enzymatic cline in mussels along Long Island Sound (Koehn, Newell, \&

87 Immermann, 1980), and microhabitat differences across tidal heights maintain balanced 88 polymorphism in limpet populations (Schmidt, Bertness, \& Rand, 2000). Such examples may 89 better reflect the realized capacity of highly dispersive marine species to adapt to stressors 90 across complex oceanographic regimes than studies of strict local adaptation (Véliz, 91 Duchesne, Bourget, \& Bernatchez, 2006).

92

93 As species expand into new environments, the process of adaptation may be mediated by the 94 complex demographic effects that often occur at range edges (Bridle \& Vines, 2007; Chuang 95 \& Peterson, 2016). Expanding populations are frequently characterized by sequential 96 bottlenecks and losses of genetic diversity caused by small groups of colonizing organisms 97 (Eckert, Samis, \& Lougheed, 2008; White, Perkins, Heckel, \& Searle, 2013; Bors, Herrera, 98 Morris, \& Shank, 2019). The success of some such populations, which multiply and spread 99 despite low genetic diversity, has been coined the "genetic paradox of invasions" (Roman \& 100 Darling, 2007). These bottlenecks can also lead to increased stochasticity at range edges, 101 causing allele surfing and other distinctive genetic patterns (Excoffier \& Ray, 2008). Gene 102 flow plays a substantial role in this process. In some cases, low-diversity edge populations 103 may be evolutionarily limited by a lack of gene flow (Sexton, Strauss, \& Rice, 2011;

104 Takahashi et al., 2016), while in others, semi-isolation at range edges permits rapid evolution 105 in organisms at the expansion front (Phillips, Brown, Webb, \& Shine, 2006; Kilkenny \& 106 Galloway, 2012; Szücs et al., 2017). High dispersal and large populations may also facilitate 107 species persistence and expansion, if functional diversity can be maintained and quickly 108 spread throughout the expanding range (Rius \& Darling, 2014). The maintenance of such 109 diversity can in theory provide the raw substrate for adaptation and permit extremely quick 110 evolutionary response to shifting conditions (Tigano \& Friesen, 2016; Llaurens, Whibley, \& 111 Joron, 2017). However, to date, the relative contributions of selection and drift as populations 112 establish in novel environments have not been explored empirically in high gene flow 113 systems. 
115 The European green crab (Carcinus maenas) along the northeast Pacific coastline presents

116 an ideal test case for untangling the dynamics of rapid marine adaptation and differentiation

117 with high potential gene flow. In this region, the species established an initial population in

118 San Francisco Bay by 1990 (Carlton \& Cohen, 2003), and spread $>1,500 \mathrm{~km}$ to Vancouver

119 Island in <10 years despite deriving from a single, significantly bottlenecked source (Tepolt et

120 al., 2009). Green crabs advanced along the coast and primarily to the north, reaching

121 northern California by 1995, southern Oregon by 1997, and Vancouver Island, British

122 Columbia by 1998 (Behrens Yamada \& Gillespie, 2008; Fig. 1). This rapid expansion was

123 associated with extremely strong positive EI Niño-Southern Oscillation (ENSO) indices in

124 1997-1998 that promoted high reproductive output, northward transport, and coastal retention

125 of larvae (Behrens Yamada et al., 2005; Behrens Yamada \& Kosro, 2010; See \& Feist, 2010).

126 Importantly, in the northeast Pacific, C. maenas are found almost exclusively in shallow

127 waters of protected embayments and not along the exposed outer coast between bays,

128 resulting in a disjunct distribution of green crab populations. This habitat distribution is similar

129 to its introduced range in South Africa, where the rocky coast is also subject to high-energy

130 wave action (Hampton \& Griffiths, 2007), but differs from its more continuous distribution in

131 other global regions (Carlton \& Cohen, 2003). The species also has a relatively wide

132 environmental tolerance and diet breadth, along with a 30-75 day pelagic larval duration

133 (Dawirs, 1985), which have contributed to its spread and establishment in six introduced

134 regions across five continents (Carlton \& Cohen, 2003; Hidalgo, Barón, \& Orensanz, 2005).

136 The importance of ENSO events in the spread and abundance of northeast Pacific C. maenas

137 suggests that both temperature and local oceanography may play substantial roles in

138 structuring the population. Decades of field surveys of abundance in both the northwest

139 Atlantic and northeast Pacific support the importance of temperature during early

140 development in driving recruitment strength: cold winters have been associated with weaker

141 recruitment and smaller cohorts of crabs than milder years (Behrens Yamada \& Kosro, 2010;

142 Welch, 1968). A global physiological study demonstrated population-level differences in adult

143 heat and cold tolerance consistent with local adaptation (Tepolt \& Somero, 2014).

144 Subsequently, transcriptomic work has identified genetic markers associated with

145 temperature tolerance on a population level (Tepolt \& Palumbi, 2020). Like many marine

This article is protected by copyright. All rights reserved 
146 species, C. maenas larvae have shown narrower temperature tolerances than adults in

147 laboratory trials, suggesting that thermal tolerance at early life stages may be particularly 148 important in shaping crab populations across different years (Dawirs, 1985; de Rivera et al., 149 2007).

150

151 Here, we use transcriptome-derived SNPs from C. maenas populations in the northeast

152 Pacific to test the roles of connectivity and selection in shaping the population structure of this 153 highly dispersive and recently introduced species. Using six sites spanning over $1,500 \mathrm{~km}$ of 154 coastline, we examine population structure and relative migration to elucidate connectivity 155 among embayments across the species' northeast Pacific range. For a few sites, we have 156 temporal samples spanning 2-5 years, which we use to examine the stability of population 157 structure over time. Finally, we test for candidate genes for selection across a thermal 158 latitudinal gradient, comparing these candidates to genes identified in a prior global study of 159 the genetic basis of thermal tolerance differences in the species. As this population was 160 founded $<35$ years ago from a single source, our data represent patterns of divergence and 161 selection that have arisen in under 20 generations.

162

\section{Materials and Methods}

Sample Collection

166 Twelve crabs were sampled from each of six sites along the northeast Pacific range of $C$.

167 maenas in 2015-2016 (Figure 1). Two of these sites (Seadrift Lagoon and San Francisco Bay, CA, USA) were sampled in both years, while the remaining sites were sampled once. We also reanalyzed raw sequence data from a prior study of crabs collected in 2011 from two sites 170 (Seadrift Lagoon, CA, USA and Barkley Sound, BC, Canada; Tepolt \& Palumbi 2015). Crabs were collected by hand or trap, and hearts were dissected and stored in RNALater at $-80^{\circ} \mathrm{C}$.

173 Extraction \& Sequencing

174 Total RNA was extracted from cardiac tissue using TRIzol (Invitrogen, Carlsbad, CA, USA) with 1-bromo-3-chloropropane (Simms, Cizdziel, \& Chomczynski, 1993). RNA was quantified using the broad-range RNA assay on a Qubit 3.0 fluorometer (Invitrogen), and up to $4 \mu \mathrm{g}$ of 
177 RNA was used to prepare individually-barcoded cDNA libraries with llumina's TruSeq

178 Stranded mRNA Library Prep Kit (Illumina, San Diego, CA, USA). Libraries were sent to the

179 University of California Berkeley's Genomics Sequencing Laboratory, where they were

180 quantified and pooled into groups of 16 multiplexed samples run on five lanes of an Illumina

181 HiSeq 4000 in 50-bp single-end reads.

182

\section{Sequence Processing and SNP Identification}

184 Raw sequences were cleaned and trimmed using Trim Galore! v0.6.4

185 (http://www.bioinformatics.babraham.ac.uk/projects/trim_galore/), a wrapper for Cutadapt v2.6

186 (Martin 2011). A nucleotide call quality cutoff of Phred $\geq 20$ was used, and reads $\leq 20 \mathrm{bp}$ after

187 adapter removal and quality trimming were discarded. A published C. maenas cardiac

188 transcriptome was used as a reference (Tepolt \& Palumbi 2015), after an expression-based

189 screening to remove poorly-supported contigs and reduce computational load. Briefly, we

190 mapped trimmed and clipped reads from Tepolt \& Palumbi 2015 back to the reference

191 transcriptome using salmon v1.2.1 (Patro, Duggal, Love, Irizarry, \& Kingsford, 2017). We

192 retained only contigs with TPM $>1$, and re-annotated these contigs using EnTAP $\vee$ 0.9.1 (Hart

193 et al. 2020), comparing all 6 reading frames against the Swissprot, TrEMBL, and $\mathrm{nr}$ protein

194 databases (downloaded March 2020). Annotations to Decapoda were prioritized with the

195 program's '--taxon' flag. Contigs with a clear taxonomic mismatch to decapods (e.g., bacteria,

196 green plants, fungi, etc.), as well as all likely mitochondrial and ribosomal contigs, were

197 identified and removed from the project after alignment to minimize non-target mapping. This

198 resulted in a clean reference transcriptome of 25,552 nuclear contigs.

199

200 Cleaned reads were mapped back to the $C$. maenas cardiac transcriptome using Bowtie2

201 v2.4.1 with default settings (Langmead \& Salzberg 2013). Picard v2.22.0 was used to sort

202 reads, identify and mark duplicate read sequences, and index the resulting bam files

203 (http://broadinstitute.github.io/picard). The Genome Analysis Toolkit (GATK) v4.1.7.0 was

204 used to identify and genotype biallelic SNPs (McKenna et al. 2010; DePristo et al. 2011).

205

206

Across all 120 samples (24 from 2011 and 96 from 2015-2016), GATK identified 163,261

207 biallelic SNPs with Phred quality scores $\geq 20$. We identified high-quality, well-supported SNPs

This article is protected by copyright. All rights reserved 
208

209

210

211

212

213

214

215 of these SNPs.

216

217 Identification of Putative Inversion Polymorphisms

218 We explored the relationship of the 9,376 high-quality SNPs to identify potential inversion

219 polymorphisms and other disproportionately large groups of SNPs in linkage disequilibirum

220 (LD). Pairwise $\mathrm{R}^{2}$ was calculated across all SNPs using the --geno-r2 and --interchrom-geno-

221 r2 options in vcftools v0.1.16 (Danecek et al. 2011). We then used the R package LDna v0.64

222 to identify networks of SNPs in large, compact clusters, setting minimum edges to 45

223 (expected for 10 closely-linked SNPs) and phi to 15 (Kemppainen et al. 2015).

224

225 We identified one large outlier LD cluster, which contained 168 SNPs from 56 different

226 contigs. To further investigate this cluster, we explored the relationship between member

227 SNPs using Principal Components Analysis (PCA) in smartPCA, implemented in Eigensoft

228 v7.2.1 (Price et al., 2006). We used the 116 individuals that had $<20 \%$ missing genotypes

229 across the 168 SNPs in this cluster. This PCA separated individuals into three clear groups

230 along $\mathrm{PC} 1$, and we calculated $\mathrm{F}_{\mathrm{IS}}$ within each of these groups to determine relative

231 heterozygosity (Kemppainen et al. 2015). These analyses strongly suggested an inversion

232 polymorphism (see Results below), so for clarity we refer to this group of 168 SNPs as an

233 "inferred inversion" throughout the rest of the manuscript. To compare the impact this putative

234 inversion had on overall population structure, we also ran a PCA on the same 116 individuals

235 using the full SNP set both with and without the 168 SNPs in the inferred inversion $(N=9,376$

236 and 9,208 SNPs, respectively).

237

238 Genetic Structure and Diversity

This article is protected by copyright. All rights reserved 
SNPs were separately screened to identify all sets of markers in linkage disequilibrium (LD) and generate a set of independent SNPs for population genomics. Pairwise $\mathrm{R}^{2}$ values (calculated above) were used to identify groups of two or more SNPs in LD at $R^{2} \geq 0.8$ using the R package igraph v1.2.4.2 (Csardi \& Nepusz 2006), and then all but one SNP in each group was removed, leaving a set of 6,848 independent SNPs. The one SNP retained from each group had the highest number of high-quality genotypes, with lower-coverage SNPs within an LD group preferentially removed. We use the term "independent" to indicate that these SNPs have been screened to remove those in strong LD, but note that these SNPs may be in LD at lower levels so are not all truly independent. Similarly, this set of 6,848 independent SNPs retained 54 of the 168 SNPs in the inferred inversion which were in lower levels of LD with each other ( $\left.R^{2}: 0.29-0.79\right)$.

Basic descriptive statistics were calculated for each site-by-year sample using the set of 6,848 independent SNPs (Table 1). Allelic richness (Ar) and private allelic richness (pAr) were determined using ADZE v1.0 (Szpiech, Jakobsson, \& Rosenberg, 2008). The R package genepop v1.1.7 was used to calculate observed and expected heterozygosity ( $\mathrm{Ho}$ and $\mathrm{He}$ ), and to calculate the inbreeding coefficient $\left(F_{I S}\right)$ and test for heterozygote excess or deficiency using Hardy-Weinberg tests (Rousset 2008). The number of polymorphic SNPs in each sample was determined using Arlequin v.3.5.2.2 (linux core implementation; Excoffier \& Lischer 2010).

To identify a subset of putatively neutral SNPs with which to examine population structure unconfounded by selection, we used BayPass v2.2 in the core model (Gautier et al. 2015), with each site-by-year sample treated as its own group. We assessed potential outliers using a simulated pseudo-observed data set of 6,848 SNPs with the parameters of the real data to set a $10 \%$ false discovery rate (FDR) threshold for SNP XtX. This conservative threshold was chosen to avoid retaining SNPs under weak selection, thus yielding a set of SNPs more likely to be truly neutral. This frequency-based approach removed all but one of the SNPs later identified as a candidate for environmental association (see below).

Genetic structure for both the independent $(N=6,848)$ and putatively neutral $(N=6,311)$ SNP 
277 We included only the most recent temporal sample from each site for an analysis of relative 278 migration using the putatively neutral SNP set (Table 1). Symmetry and relative magnitude of 279 migration between sites was assessed using the 'divMigrate' function in the R package 280 'diveRsity' v1.9.90, with the Nm method and 1,000 bootstraps (Sundqvist, Keenan,

sets was assessed with smartPCA. Pairwise $F_{S T}$ was calculated between all site-by-year groups according to Weir \& Cockerham's (1984) approach using the R package 'StAMPP' v1.6.1 with both the independent and putatively neutral SNP sets (Pembleton, Cogan, \& Forster, 2013). Significance was assessed using 10,000 permutations, and resulting p-values were adjusted for multiple tests using a Benjamini-Hochberg false discovery rate correction (Benjamini \& Hochberg 1995).

Zackrisson, Prodöhl, \& Kleinhans, 2016). This approach, which calculates relative directional migration, was chosen because it is more robust if populations do not perfectly satisfy some of the assumptions underlying approaches to quantify an effective migration rate (e.g., island model, mutation-drift equilibrium).

All analyses showed strong separation of a single site, Seadrift Lagoon, from all other sites (see Results below). Because of this genetic distinctiveness, isolation-by-distance (IBD) analysis excluded pairwise comparisons with Seadrift Lagoon, focusing only on the remaining five "open" sites. Pairwise $F_{S T}$ values were used to plot IBD between sites, using along-shore distance calculated at $50 \mathrm{~km}$ resolution with the USA map from GADM supplemented with Google Maps for distances $<50 \mathrm{~km}$ (gadm.org). When comparisons spanned San Francisco Bay and the Strait of Juan de Fuca, distances were calculated across the mouths of these features. IBD was plotted using five different SNP sets, to explore different potential drivers of latitudinal structure along the coast: 1) 6,848 independent SNPs, 2) 6,311 putatively neutral SNPs, 3) 54 "independent" SNPs in the inferred inversion, 4) 6,794 independent SNPs excluding the 54 independent SNPs in the inferred inversion 5) 144 outlier SNPs identified among the five "open" sites with BayPass (see Results). The significance of these relationships was assessed using linear regression in $R$.

\section{Markers under Selection}

This article is protected by copyright. All rights reserved 
301 We identified SNPs potentially under environmental selection using BayPass and

302 Redundancy Analysis (RDA). We ran these tests using only the five open sites, excluding

303 Seadrift Lagoon, to identify markers potentially driving the observed signal of IBD and

304 latitudinal structuring along the coast. For this testing we used a single sample, collected in

305 2015-2016, from each site: 6,662 SNPs of the full 6,848 SNP set were polymorphic in these

306 five samples and were used for tests of selection. Tested covariates included site latitude (as

307 Cartesian Y-values) and winter and summer sea surface temperature (SST). Temperature

308 data were derived from NOAA's OI SST V2 High Resolution Dataset provided by the

309 NOAA/OAR/ESRL PSD, Boulder, Colorado, USA, from their website at

310 https://www.esrl.noaa.gov/psd/ (Reynolds et al. 2007). Daily temperatures were averaged

311 over the 2 years prior to sampling, and were determined for the nearest $0.25^{\circ}$ grid location to

312 each study site for January (winter) and July (summer).

313

314 In BayPass, we first ran a core model analysis to identify frequency outlier SNPs, then used

315 the auxiliary covariate model to test for associations between allele frequencies and latitude

316 and winter and summer SST (Gautier 2015). Covariates were scaled, and we used an Ising

317 prior of 0 since the physical order of contigs is unknown. We considered any SNP with Bayes

318 factor $(B F) \geq 15 \mathrm{~dB}$ to be a candidate for selection with respect to a given covariate.

319

320 We ran an RDA on individual genotypes using the R package 'vegan' v2.5-6 (Oksanen et al.

321 2019), with missing genotypes imputed to be the most common observed. Few individual

322 genotypes were missing in our data set: genotyping was $\geq 90 \%$ complete for $97.1 \%$ of SNPs,

323 and no single sampling site was missing $>4$ individual genotypes at any SNP. We used

324 latitude and summer temperature as covariates (RDA formula $=$ individual genotypes $\sim \mathrm{Y}+$

325 July SST); winter temperature was excluded as it was strongly correlated with latitude $\left(R^{2}=\right.$

$3260.79 ; p=0.03)$. We considered any SNP >3 SD outside the mean loading for its RDA axis to

327 be a candidate for selection (e.g., Forester et al., 2018).

328

329 SNPs were considered strong candidates for selection if they were identified by both BayPass and RDA. Latitude is largely correlated with SST in this data set, due both to the strongly

331 linear north-south arrangement of sites along the coast and to the relative coarseness of the

This article is protected by copyright. All rights reserved 
332 satellite-derived temperature data. Because of this confounding, we treated all SNPS

333 identified as candidates for association with either latitude or temperature interchangeably. To

334 visualize these relationships, candidate SNPs were tested for linear correlation between

335 minor allele frequency and latitude or temperature.

336

\section{Potential Function of Candidate SNPs}

338 Candidate SNPs were examined for their potential impact on protein structure, to provide an 339 initial idea of SNPs that were particularly likely to affect organismal function. Open Reading 340 Frames (ORFs) and corresponding coding sequences for all contigs were predicted using 341 OrfPredictor v3.0 (Min, Butler, Storms, \& Tsang, 2005); as many contigs could not be 342 annotated, sequence data alone was used to predict ORFs. Predicted sequences were then 343 used to class the impact of a given SNP on the resulting protein sequence (untranslated, 344 synonymous, or non-synonymous) using a custom python script. Of the 9,376 high-quality 345 SNPs, we predicted that 4,339 were in the untranslated regions of the mRNA and two were in 346 contigs for which an ORF could not be predicted. Of the putatively coding SNPs, 3,843 were 347 predicted to be synonymous and 1,192 to be non-synonymous. We examined SNP 348 substitution patterns for all 9,376 candidate SNPs prior to LD screening. While putatively 349 linked SNPs were removed from the data set prior to selection analysis, they could potentially 350 be driving any relationships we detected in SNPs with which they are in strong LD.

352 Data manipulation and plotting were done using the data.table and ggplot2 packages in $\mathrm{R}$ 353 (Wickham 2009; R Core Team 2016; Dowle \& Srinivasan 2017).

355 Results

356

\section{Inferred Inversion Polymorphism}

358 Linkage disequilibrium network analysis identified one single outlier LD cluster nested in one 359 compound outlier LD cluster (Figure 2A-B). The compound outlier LD cluster, which we refer 360 to as an "inferred inversion", contained 168 SNPs at an LD of $R^{2} \geq 0.29$. PCA of these 168 361 SNPs split individuals into three discrete groups along the first principal component, 362 explaining $73.08 \%$ of variance $(p=0.001$; Figure $2 C)$. While individuals from most sites 
363 appeared in all three groups, the left-most group contained predominantly British Columbia 364 and Seadrift Lagoon while the right-most group contained predominantly Elkhorn Slough and 365 San Francisco Bay. This pattern of three distinct groups explaining the majority of structure, 366 with no discrete partitioning of sites, is diagnostic of a region of the genome where 367 recombination is reduced (Kemppainen et al. 2015). In that case, each group represents a 368 karyotype: homozygotes on the left and right sides of PC1, and heterozygotes midway 369 between. Analysis of $F_{I S}$ within each of these groups supports this conclusion, with values 370 near zero in the putative homozygotes (indicating Hardy-Weinberg equilibrium) and strongly 371 negative in the putative heterozygotes (indicating an excess of heterozygous individuals; 372 Figure 2D). Overall $F_{I S}$ is lower in the middle than in the left or right groups ( $p<0.0001$ for

373 both comparisons), while the left and right groups are not significantly different from each 374 other $(p=0.1)$.

375

376 Genetic structure over all SNPs showed a significant divide between Seadrift Lagoon and the 377 other five sites, both with and without the 168 SNPs in the inferred inversion $(p<0.0001$; 378 Figure 2E-F). With the full set of 9,376 SNPs, individuals in both Seadrift Lagoon and the 379 remaining five "open" sites were further subdivided into three clusters according to their 380 inferred inversion genotype $(p<0.0001$; Figure $2 C, E)$. When the 168 SNPs in the inferred 381 inversion were removed, this three-part structure disappeared and the second principal 382 component was no longer significant $(p=0.09$; Figure $2 F)$.

SNP Selection and Genetic Diversity

Of the full 9,376 high-quality SNP set, 3,962 SNPs comprised 1,434 groups in LD with $R^{2} \geq$ 0.8; all but one SNP was removed from each group to create a set of 6,848 "independent" SNPs. This screening differs from the earlier LDna analysis, which sought to identify large clusters of LD; by contrast, this approach intends simply to remove bias to population structure measurements from including any sets of SNPs in strong LD. The majority of these groups ( $N=839$ ) comprised small numbers of SNPs in the same contig. The largest of these 391 groups by far included 77 SNPs from the inferred inversion; no other groups contained $>13$ SNPs. We note that this analysis did not identify all 168 SNPs in the inferred inversion as being in the same group, since some of those SNPs are in LD with others at $R^{2}<0.8$; 
consequently, the set of 6,848 independent SNPs includes 54 SNPs in the inferred inversion.

395

396 After removing SNPs in strong LD, we had a final working panel of 6,848 high-quality, 397 independent SNPs. BayPass identified 537 of these SNPs as potentially under selection at 398 FDR $\leq 0.1$ across all site-by-year samples; these SNPs were removed to construct a panel of 3996,311 putatively neutral SNPs for selected downstream analyses.

401 Allelic richness ranged from 1.669-1.711 (Table 1); it was significantly lower in Seadrift 402 Lagoon than in all other sites in all years ( $p \leq 0.005$; Table 1). Private allelic richness was low, 403 ranging from $0.00438-0.00771$; seven pairwise comparisons were significant, all comparing

404 Seadrift Lagoon in 2011 or 2016 with non-Seadrift Lagoon sites ( $p<0.05$ for all 405 comparisons). Lower allelic richness in Seadrift Lagoon reflects a lower number of 406 polymorphic SNPs there than in all other sites (Table 1). All samples showed a significant 407 heterozygote excess.

408

409 Population Structure and Migration

$410 \mathrm{~F}_{\mathrm{ST}}$ was significant between most sample pairs when using the 6,848 independent SNP set

411 (pairwise $\mathrm{F}_{\mathrm{ST}}$ excluding temporal comparisons: 0.00058-0.027; SI Table S1). By contrast, 412 when using the 6,311 putatively neutral SNPs nearly all significant comparisons were 413 between Seadrift Lagoon samples and all other sites (pairwise F $_{\text {ST }}$ including Seadrift: 0.0081414 0.016; pairwise F $_{\text {ST }}$ excluding Seadrift: -0.0021-0.0044; SI Table S2). There was no evidence 415 for differentiation within any temporal comparison across years with the putatively neutral 416 SNP set (pairwise FST: -0.0020-0.0014; SI Table S2). Principal components analysis

417 reinforced these patterns, with the first component separating Seadrift Lagoon from all other 418 sites with both the independent and neutral SNP sets $(6,848$ independent SNPs: loading = $4192.75 \%, p<0.0001 ; 6,311$ neutral SNPs: loading $=2.07 \%, p<0.0001 ;$ Figure 3A,B). The 420 second component was significant only with the independent SNP set (loading $=1.53 \%, p<$ 421 0.0001), and spread non-Seadrift Lagoon sites along a rough north-south axis (Figure 3A). 422 With the neutral SNP set, this pattern collapsed ( $p>0.05)$, with near-complete overlap among 423 all non-Seadrift Lagoon samples (Figure 3B). While Seadrift Lagoon had significantly lower 424 allelic richness than all other sites, there were no significant differences among the remaining 
425 open sites (Figure 3C).

426

427 To test a realistic migration scenario, we estimated relative migration using only the most 428 recent sample from each site. Estimates of relative migration between sites (using 6,311

429 neutral SNPs only) demonstrated similar and symmetrical migration among all sites except

430 Seadrift Lagoon (Figure 3D). Consistent with Seadrift Lagoon's distinctiveness, we found 431 evidence for reduced migration both into and out of this site relative to the rest of our study 432 sites (Figure 3D). The approach we used sets the maximum observed migration to 1 and 433 scales the rest of the migration estimates accordingly. Between all five open sites, we 434 observed values of $88-100 \%$ of maximum observed migration, while estimated migration 435 between Seadrift Lagoon and all other sites ranged from 68-78\% of the maximum. We note, 436 however, that it is impossible to fully differentiate between ongoing low-level migration and 437 recent divergence (with no ongoing migration) given the recent history of green crabs in the 438 northeast Pacific.

439

440 A test of IBD along the five "open" sites (excluding Seadrift Lagoon) recapitulated the north441 south pattern observed for these sites in the PCA, but only when putatively selected SNPS 442 were included. The 6,848 independent SNP set showed a significant pattern of IBD $\left(\mathrm{R}^{2}=\right.$ $443 \quad 0.38 ; p=0.0002)$, which collapsed completely with the 6,311 neutral SNP set $\left(R^{2}=-0.02 ; p=\right.$ $4440.4)$ or when removing only the 54 SNPs in the inferred inversion $\left(R^{2}=0.00 ; p=0.3\right.$; Figure 445 4A). However, we note that overall differentiation for all of these SNP sets was very low, with 446 a maximum pairwise $F_{S T}$ of 0.0066 . IBD was much stronger in the 144 outlier SNPs

447 (frequency outliers across the five open sites), and stronger still in the 54 "independent" SNPs 448 in the inferred inversion. The 144 frequency outliers had significant IBD with a maximum 449 pairwise $F_{S T}$ of $0.16\left(R^{2}=0.38 ; p=0.002\right)$, while the SNPs in the inferred inversion showed a 450 strong IBD pattern $\left(R^{2}=0.77 ; p<0.0001\right)$ with a maximum pairwise $F_{S T}$ of 0.24 between the 451 most distant two sites (Figure 4B).

452 453 Selection in the Northeast Pacific

454 All tests for selection were run with only the most recent temporal sample from the five open 455 sites, using the 6,662 SNPs of the 6,848 independent SNP set that were variable in these five 
456

457

458

459

460

461

462

463

464

465

466

467

468

469

470

471

472

473

474

475

476

477

478

479

480

481

482

483

484

485

486

samples. Using the BayPass core model, 144 unlinked SNPs were frequency outliers at FDR $\leq 0.05$ among these five samples. The BayPass covariate test identified 26 SNPs related to latitude, 26 SNPs associated with January SST, and six SNPS associated with July SST (SI Figure S1). Seventeen of these SNPs were associated with two or more traits, for a total of 40 unique environmentally associated SNPs. Some associations were quite strong, with seven SNPs associated with latitude and/or winter temperature at BF $\geq 25 \mathrm{~dB}$. No SNPs were strongly associated with July SST (SI Figure S1).

The Redundancy Analysis (RDA) showed that latitude fell almost perfectly along the first RDA axis, while July SST fell between the first and second axes (SI Figure S2). In this test, association with latitude also represents association with January SST, which was not included as the two measures were strongly correlated. The full RDA was significant $(F=$ $1.10, p=0.001)$, as were both resulting RDA axes $(R D A 1: F=1.12, p=0.001 ; R D A 2: F=$ 1.09, $p=0.003$ ). Variance Inflation Factors were less than 2 for both axes, indicating no potential confounding from multicollinearity in the environmental variables. In total, 23 SNPs were identified as outliers on one of the two RDA axes: of these, 15 were most strongly associated with latitude while 8 were most strongly associated with July SST (SI Figure S2).

We took as our most likely candidate markers for selection those associated with latitude or temperature in both the BayPass and RDA analyses. In total, 13 SNPs overlapped between the 40 identified with BayPass and the 23 identified with RDA. Of these, two were excluded because of rarity (maximum per-population MAF $\leq 0.3$ ). Ten of the remaining 11 candidate SNPs were in the inferred inversion; these were retained in the independent SNP set because they were not in strong enough LD with each other to have been removed (threshold for strong LD: $R^{2} \geq 0.8$ ). For visualization purposes, we generated "extended genotypes" for the inferred inversion by classing individuals based on group membership in a PCA of all 168 SNPs (Figure 2C). As noted earlier, individuals belonging to the left-most group were classed as homozygotes for the minor allele, those in the middle group as heterozygotes, and those in the right-most group as homozygotes for the major allele. For the open sites (minus Seadrift Lagoon), both the inferred inversion and the independent candidate SNP had MAFs that were significantly correlated with latitude (Figure 5). Interestingly, for the inferred inversion, MAF in

This article is protected by copyright. All rights reserved 
492 The ten candidate SNPs in the inferred inversion were in strong LD with a number of SNPs

Seadrift Lagoon fell outside the predicted line, instead having a MAF closer to that of British Columbia and predicted to belong to a more northern and/or colder site (Figure 5A). By contrast, Seadrift MAF fell along the line predicted by MAF in the open sites for the one candidate SNP outside this inferred inversion (Figure 5B). removed from the unlinked data set, for a total of 97 SNPs in 39 different contigs (SI Table S3). Because we ran selection analyses on a set of SNPs that had been pruned to remove those in strong LD, any of these 97 SNPs (or other linked variation we did not retain after SNP QC) could be driving the observed pattern of selection. Of the 97 candidate SNPs in the inferred inversion, $18.6 \%$ (18/97) were predicted to change the amino acid sequence of the resulting protein compared to $12.7 \%(1,192 / 9,374)$ in the full 9,376 SNP set (before linkage filtering). The 18 predicted non-synonymous SNPs in the inferred inversion were in contigs annotated as: hypoxia inducible factor 1 alpha (2 SNPs), NAD-dependent protein deacylase, fibrillin-2-like isoform $X 4$, ubiquinol-cytochrome-c reductase complex assembly factor $1, \mathrm{SMB}$ domain-containing protein (3 SNPs), protein lingerer-like, prosaposin-like, cartilage oligomeric matrix protein, ATP-dependent RNA helicase DDX56, one uncharacterized protein, and four unannotated contigs (5 SNPs). The one candidate SNPs not in the inferred inversion was predicted to be a synonymous substitution in protein SGT1 homolog (SI Table S4).

\section{Discussion}

The expansion of $C$. maenas along the northeast Pacific coast is a canonical example of the "genetic paradox of invasions". The population has been demonstrably successful, rapidly expanding along $>1,500 \mathrm{~km}$ of coastline despite deriving from a single genetically depauperate source. Here, we have shown that variation in a specific region of the genomean inferred chromosomal inversion previously associated with cold tolerance in the species appears to be under strong latitudinal selection in this system. Population genomics shows that this putative selection is occurring against a backdrop of high oceanographic connectivity. Our sampling comprises five discrete bays connected by high larval gene flow, and a single oceanographically isolated population that has diverged genetically in $<20$ generations, 
518 demonstrating the importance of larval connectivity in mediating population dynamics in range 519 expansion. Comparison with older data shows that genetic structure and diversity have 520 remained stable across at least one generation, suggesting large population sizes and 521 consistent recruitment pools over time. We propose that this high connectivity, a hallmark of 522 the species, may have promoted the initial evolution of this inferred inversion as a balanced 523 polymorphism in Europe and may be critical to its persistence and spread in introduced 524 populations. In turn, the variation protected by this inversion may play a key role in $C$. 525 maenas' success across wide environmental gradients in its introduced range despite 526 significant reductions in overall genetic diversity.

\section{7}

528 Chromosomal Inversions and Adaptation

529 The importance of chromosomal architecture, particularly chromosomal inversions, has been 530 increasingly recognized in selection with gene flow in natural systems (Tigano \& Friesen, 531 2016). Inversion polymorphisms can be extensive, and can maintain extended genotypes at 532 hundreds to thousands of genes by suppressing recombination in heterozygotes (Kirkpatrick, 533 2010). While inversion is not the only mechanism by which recombination can be reduced, it 534 is generally believed to be most effective in maintaining large blocks of co-adapted genes 535 over time (Lamichhaney \& Andersson, 2019). This recombination suppression, in turn, 536 permits suites of gene variants to evolve and be inherited together, capturing complex multi537 gene interactions in a single "supergene" (Thompson \& Jiggins, 2014).

539 Inversions have been directly associated with important differences in ecotype across small 540 spatial scales in interbreeding populations, suggesting that this type of chromosomal 541 architecture can promote highly localized selection (Westram et al., 2018; Huang et al. 2020). 542 In some systems, including monkeyflowers and Atlantic cod, important differences in life 543 history have been linked to just one or two inversions (Twyford \& Friedman 2015; Kirubakaran 544 et al. 2016). Pioneering work on Drosophila identified a number of inversions showing clinal 545 associations with latitude and temperature; such relationships have been shown to develop 546 rapidly in introduced populations (Balanyà et al. 2006), and to predictably "cycle" in frequency 547 with changing seasonal temperatures within a population (Kapun et al. 2016). Together, this 548 growing body of work suggests that inversions can act as targets of spatial balancing 
selection in systems where the scale of gene flow exceeds the scale of environmental heterogeneity, providing an effective mechanism by which such species can respond to their environments on very fast time scales (Sanford \& Kelly, 2011; Tigano \& Friesen, 2016).

We have previously proposed that a chromosomal inversion or another genomic region of reduced recombination is likely under selection to temperature in C. maenas (Tepolt \& Palumbi, 2020). Many of the same SNPs identified in the inferred inversion in this study were independently found to be part of the putative inversion in that prior global study, indicating that the same likely inversion is associated with cold tolerance globally and with latitudinal divergence along the northeast Pacific. In the earlier study, candidate SNPs were variable in the European native range and showed similar evidence of strong linkage disequilibrium and reduced recombination there (Tepolt \& Palumbi, 2020). This demonstrates that rapid selection in the northeast Pacific is acting primarily on standing variation that arose in the original source population, ruling out post-invasion dynamics as a driver for this linkage disequilibrium (Slatkin, 2008).

\section{Population Structure and Temporal Dynamics}

In the northeast Pacific, C. maenas has lost significant overall genetic diversity compared to its East Coast source or the species' native range in Europe (Tepolt \& Palumbi, 2015). However, diversity is largely consistent across its northeast Pacific range, with no losses at the range edges relative to the San Francisco source (Figure $3 \mathrm{C}$ ). While diversity loss in expanding range edges has been widely noted and is a common expectation (Vucetich, Waite, \& Nunney, 1997; Eckert et al., 2008), it may be mediated by large population sizes and high gene flow (Excoffier, Foll, \& Petit, 2009). Green crabs spread rapidly but episodically up the coast from the initial point of introduction in San Francisco Bay, with the largest expansion in conjunction with the strong 1997-1998 ENSO event (Behrens Yamada et al., 2005). Further research has shown that strong crab cohorts have corresponded with warmer waters and enhanced northward nearshore currents (Behrens Yamada, Peterson, \& Kosro, 2015). Modeling has shown that larval dispersal trajectories likely vary considerably both within and between years depending on hydrography, with larvae potentially traveling both north and south (Brasseale, Grason, McDonald, Adams, \& MacCready, 2019). Together with this prior 
580 work, our data suggest that periodic transport events are sufficient to maintain consistent

581 genetic diversity and structure across time and space in these open bays despite the variable 582 nature of recruitment in the system.

583

584 All of our data point to ongoing high gene flow across the range of the recent and rapid $C$.

585 maenas expansion in the northeast Pacific, with one exception (Figure 3). This exception is

586 Seadrift Lagoon, which is small, isolated from the adjacent Bolinas Lagoon, and now

587 oceanographically separated from the larger coastal circulation (Ritter, 1970). Green crabs

588 were first reported in Seadrift Lagoon in 1993 (Tepolt et al., 2009), and by 2011, our first year

589 of sampling, they had lost significant genetic diversity relative to the rest of our study sites

590 (Tepolt \& Palumbi, 2015; Figure 3C). Our current sampling does not include Bolinas Lagoon,

591 the larger lagoon to which Seadrift Lagoon was historically connected but to which it is now

592 linked only by culverts with managed water flow. However, a prior study of the temporal

593 dynamics of C. maenas using microsatellites found no evidence for diversity loss in Bolinas

594 Lagoon relative to any other sites, including San Francisco Bay and Bodega Bay (Tepolt et

595 al., 2009). Data from experimental removal work in Seadrift Lagoon suggest that population

596 dynamics in the lagoon are highly localized (Grosholz et al., 2021). Given the observed

597 openness of the other bays, we would expect structure and diversity to homogenize quickly if

598 Seadrift Lagoon were receiving substantial larval inputs from surrounding, higher-diversity

599 populations.

600

601 Genetic structure and diversity appear to be stable over time at least for the 5-6 years

602 covered by our sampling, with no significant changes in $\mathrm{F}_{\mathrm{ST}}$ or allelic richness across years

603 within a site. The lifespan of C. maenas is no more than 4-6 years (Behrens Yamada et al., 604 2005), and we did not sample the largest and oldest individuals, so the 2011 and 2016

605 samples represent non-overlapping generations. Structure and diversity were stable in both

606 sites we sampled across generations, including one of the well-mixed open sites (Barkley

607 Sound), and the putatively isolated Seadrift Lagoon.

608

609 High Gene Flow and Rapid Selection

610 Against a background of high gene flow and negligible neutral genetic structure among most

This article is protected by copyright. All rights reserved 
611 sites along the northeast Pacific, we observed a north-south gradient in the system driven by

612 an inferred inversion polymorphism (Figure 3A, 4). While it is very difficult to disentangle 613 selection from allele surfing at range expansion (Excoffier et al., 2009; Lotterhos \& Whitlock, 614 2014), and we cannot say conclusively that allele surfing does not play a role in this IBD 615 pattern, several lines of evidence suggest that we are detecting a genuine signal of selection. 616 Green crabs along the northeastern Pacific coast comprise large populations with high 617 dispersal and gene flow, traits that limit the potential for successful allele surfing (Excoffier et 618 al., 2009; Goodsman, Cooke, Coltman, \& Lewis, 2014). These traits are reflected in similar 619 levels of genetic diversity across all of the populations in the more highly connected "open" 620 bays (Figure 3C). In addition, while $C$. maenas has spread primarily northward from its site of 621 first introduction, the sole area of southern spread with an established population (Elkhorn 622 Slough) shows MAF consistent with increases of "southern" alleles. This is contrary to the 623 expectations of allele surfing, in which a species expanding along multiple range edges is 624 expected to demonstrate different "favored" alleles in each direction by chance (Demastes, 625 Hafner, Hafner, Light, \& Spradling, 2019).

627 Finally, many of the same SNPs found in the inferred inversion driving latitudinal divergence 628 were previously identified as belonging to a putative supergene strongly associated with 629 thermal physiology in a dataset spanning six native- and invasive-range $C$. maenas 630 populations (Tepolt \& Palumbi, 2020). While winter SST and latitude cannot be disentangled 631 in our current dataset, this previous study provided stronger evidence for temperature in 632 driving selection. Together with the minimal neutral structure across the open sites, we 633 suggest that the inferred inversion in our study is very likely maintained as a balanced 634 polymorphism under strong selection to temperature.

636 Recent research using fine-scale sampling covering multiple years, life stages, and sampling 637 sites has shown that targets of selection can vary across all of these scales in high-dispersal 638 systems, contributing to patterns that may appear chaotic with less thorough sampling (Thia 639 et al., 2021). While "chaotic genetic patchiness" is often a hallmark of such systems (Eldon et 640 al., 2016), we did not observe that in our sampling (Figure 3A,B; 5). This may be due in part 641 to the domination of the selective signal in our system by a single large genomic region with 
642 what is likely a high selection coefficient, in concert with our sampling of adults. If selection at 643 this region is acting primarily on the dispersive larval stage, our sampling will reflect the 644 aftermath of this selection rather than the initial pool of recruits (Sanford \& Kelly, 2011). 645 Similar patterns of balanced polymorphism have been shown in two classic examples of 646 selection on large-effect alleles in early life stages in barnacles and mussels (Koehn et al., 647 1980; Schmidt \& Rand, 2001).

648

649 For SNPs in the inferred inversion, MAF at Seadrift Lagoon did not follow the predicted 650 relationship based on the open sites and was instead characteristic of higher latitudes (Figure 651 5A). While speculative, we suggest that Seadrift Lagoon's isolation means that crabs at this 652 site are responding to the environment on an extremely local scale as opposed to those in 653 other bays, whose larvae may travel hundreds of kilometers through coastal currents 654 (Behrens Yamada et al., 2005; Brasseale et al., 2019). Seadrift Lagoon is shallow and small, 655 and may experience more extreme (and especially colder) temperatures than nearby open 656 bays. Finer-scale temperature data from within Seadrift Lagoon, rather than larger-scale 657 satellite-derived SST data, would help to test this hypothesis.

659 While prior work uncovered a robust link between this inferred inversion and physiological 660 cold tolerance, its ability to identify rapid selection after invasion was limited by a complex 661 invasion history and differences in genetic background across the six studied populations on 662 three coastlines. Here, we demonstrate that this inferred inversion recapitulates predicted 663 allele frequency correlation with temperature in an otherwise homogenous, highly 664 bottlenecked introduced population over a period of 10-20 generations. This study provides 665 evidence for very rapid adaptive change in an introduced species with extremely limited 666 genetic diversity, and proposes this adaptation was facilitated by variation at a single 667 inversion polymorphism that evolved and is likely maintained as a balanced polymorphism in 668 the native range.

\section{Conclusions}

671 We have long known that diversity is important to population resilience in the face of changing 672 conditions (Reed \& Frankham, 2003). The genetic paradox of invasions is that we do 
673 occasionally find incredibly successful, non-clonal populations that have passed through

674 severe bottlenecks, dramatically decreasing their genetic diversity relative to their sources

675 (Kohn, Murphy, Ostrander, \& Wayne, 2006). Perhaps we can partially resolve this paradox by 676 considering that diversity at specific parts of the genome (rather than genome-wide diversity)

677 may play a critical role in resilience (Estoup et al., 2016). Simulations have shown that 678 expanding populations can adapt via a few variants of large effect even in the face of low 679 overall diversity (Gilbert \& Whitlock, 2017). High dispersal, which characterizes many marine 680 systems, may promote the evolution of a few alleles of large effect via genomic mechanisms 681 such as inversion polymorphisms (Tigano \& Friesen, 2016). While balanced polymorphisms 682 at large-effect alleles may permit these populations to respond extremely quickly to their local 683 environments, they may also be a huge benefit to the survival and success of introduced 684 populations.

685

686 Introduced marine species often exhibit an extensive dispersal ability, resulting from close 687 association with human-built marine infrastructure or a high capacity for larval transport 688 (Carlton \& Geller, 1993; Wilson, Dormontt, Prentis, Lowe, \& Richardson, 2009). For the latter, 689 high dispersal and gene flow may have a twofold effect wherein the same traits that allow a 690 species to reach and spread in a new range may also promote the evolution of genomic 691 mechanisms (i.e., balanced polymorphisms) that facilitate rapid adaptation to a range of 692 environmental conditions (Tigano \& Friesen, 2016). This is similar to the idea that periodic 693 disturbance promotes the evolution of traits that enhance invasiveness and increase the 694 likelihood of success in novel environments (Lee \& Gelembiuk, 2008; Ketola et al., 2013). We 695 propose that an analogous process may be at work in highly dispersive marine invaders. 696 Such species may be able to evolve and maintain balanced polymorphisms across broad 697 environmental gradients in their native ranges, giving them the substrate for rapid adaptive 698 change as they expand in new environments.

699

\section{Acknowledgments}

701

We thank S. Yamada, J. Gonzalez, R. Jeppeson, I. McGaw, and E. Clelland for their assistance in obtaining genetic samples. We also thank the National Science Foundation

This article is protected by copyright. All rights reserved 
704 (OCE-RAPID \#1514893 to EDG, CD and GM), Smithsonian Institution (Hunterdon Fund to

705 GMR), and The Penzance Endowed Fund for Assistant Scientists (to CKT) for their support of 706 this project.

707

\section{References}

709 Balanyà, J., Oller, J. M., Huey, R. B., Gilchrist, G. W., \& Serra, L. (2006). Global genetic $710 \quad$ change tracks global climate warming in Drosophila subobscura. Science, 313, 1773711 1775. https://doi.org/10.1126/science.1131002

712 Behrens Yamada, S., \& Gillespie, G. (2008). Will the European green crab (Carcinus

713 maenas) persist in the Pacific Northwest? ICES Journal of Marine Science, 65, 725-729.

714 https://doi.org/10.1093/lcesjms/Fsm191

715 Behrens Yamada, S., \& Kosro, P. (2010). Linking ocean conditions to year class strength of 716 the invasive European green crab, Carcinus maenas. Biological Invasions, 12, 1791717 1804. https://doi.org/10.1007/s10530-009-9589-y

718 Behrens Yamada, S., Peterson, W., \& Kosro, P. (2015). Biological and physical ocean 719 indicators predict the success of an invasive crab, Carcinus maenas, in the northern 720 California Current. Marine Ecology Progress Series, 537, 175-189.

721 https://doi.org/10.3354/meps11431

722 Behrens Yamada, S., Dumbauld, B. R., Kalin, A., Hunt, C. E., Figlar-Barnes, R., Randall, A. 723 (2005). Growth and persistence of a recent invader Carcinus maenas in estuaries of the 724 northeastern Pacific. Biological Invasions, 7, 309-321. https://doi.org/10.1007/s10530$725 \quad 004-0877-2$

726 Benjamini, Y., \& Hochberg, Y. (1995). Controlling the false discovery rate: a practical and 727 powerful approach to multiple testing. Journal of the Royal Statistical Society B, 57, 289728 300.

729 Blackburn, T. (2008). Using aliens to explore how our planet works. Proceedings of the National Academy of Sciences U.S.A. 105, 9-10. https://doi.org/10.1073/pnas.0711228105

732 Brasseale, E., Grason, E., McDonald, P. S., Adams, J., \& MacCready, P. (2019). Larval 
750 Csardi, G., \& Nepusz, T. (2006). The igraph software package for complex network research, 751 InterJournal, Complex Systems, 1695. http://igraph.org

752 Danecek, P., Auton, A., Abecasis, G., Albers, C. A., Banks, E., Depristo, M. A., ... 1000 753 Genome Project Analysis Group. (2011). The variant call format and VCFtools.

transport modeling support for identifying population sources of European green crab in the Salish Sea. Estuaries and Coasts, 42, 1586-1599. https://doi.org/10.1007/s12237019-00586-2

Bridle, J., \& Vines, T. (2007). Limits to evolution at range margins: when and why does adaptation fail? Trends in Ecology and Evolution, 22, 140-147. https://doi.org/10.1016/j.tree.2006.11.002

Bors, E., Herrera, S., Morris, J., \& Shank, T. (2019). Population genomics of rapidly invading lionfish in the Caribbean reveals signals of range expansion in the absence of spatial population structure. Ecology and Evolution, 9, 3306-3320. https://doi.org/10.1002/ece3.4952

Carlton, J., \& Cohen, A. (2003). Episodic global dispersal in shallow water marine organisms: the case history of the European shore crabs Carcinus maenas and C. aestuarii. Journal of Biogeography, 30, 1809-1820. https://doi.org/10.1111/j.1365-2699.2003.00962.x

Carlton, J., \& Geller, J. (1993). Ecological roulette: the global transport of nonindigenous marine organisms. Science, 261, 78-82.

Chuang, A., \& Peterson, C. (2016). Expanding population edges: theories, traits, and tradeoffs. Global Change Biology, 22, 494-512. https://doi.org/10.1111/gcb.13107 Bioinformatics, 27, 2156-2158.

Dawirs, R. (1985). Temperature and larval development of Carcinus maenas (Decapoda) in the laboratory; predictions of larval dynamics in the sea. Marine Ecology-Progress Series, 24, 297-302. https://doi.org/10.3354/meps024297

758 Demastes, J., Hafner, D., Hafner, M., Light, J., \& Spradling, T. (2019). Loss of genetic diversity, recovery and allele surfing in a colonizing parasite, Geomydoecus aurei. Molecular Ecology, 28, 703-720. https://doi.org/10.1093/oxfordjournals.jhered.a111627 
761 DePristo, M., Banks, E., Poplin, R., Garimella, K. V., Maguire, J. R., Hartl, C. ... Daly, M. J. 762 (2011) A framework for variation discovery and genotyping using next-generation DNA 763 sequencing data. Nature Genetics, 43, 491-498.

764 de Rivera, C., Hitchcock, N. G., Teck, S. J., Steves, B. P., Hines, A. H., Ruiz, G. M. (2007).

765 Larval development rate predicts range expansion of an introduced crab. Marine Biology, 766 150, 1275-1288. https://doi.org/10.1007/s00227-006-0451-9

767 Dowle, M., \& Srinivasan, A. (2019). data.table: Extension of 'data.frame'. R package version

768 1.12.8. https://CRAN.R-project.org/package=data.table

769 Eckert, C., Samis, K., \& Lougheed, S. (2008). Genetic variation across species' geographical

770 ranges: the central-marginal hypothesis and beyond. Molecular Ecology, 17, 1170-1188. https://doi.org/10.1111/j.1365-294X.2007.03659.x

772 Eldon, B., Riquet, F., Yearsley, J., Jollivet, D., \& Broquet, T. (2016). Current hypotheses to 773 explain genetic chaos under the sea. Current Zoology, 62, 551-566.

774 https://doi.org/10.1093/cz/zow094

775 Ellingson, R., \& Krug, P. (2016). Reduced genetic diversity and increased reproductive 776 isolation follow population-level loss of larval dispersal in a marine gastropod. Evolution, $777 \quad 70,18-37$. https://doi.org/10.1111/evo

778 Estoup, A., Ravigné, V., Hufbauer, R., Vitalis, R., Gautier, M., \& Facon, B. (2016). Is there a 779 genetic paradox of biological invasion? Annual Review of Ecology, Evolution, and 780 Systematics, 47, 51-72. https://doi.org/10.1146/annurev-ecolsys-121415-032116

781 Excoffier, L., Foll, M., \& Petit, R. (2009). Genetic consequences of range expansions. Annual 782 Review of Ecology, Evolution, and Systematics, 40, 481-501. https://doi.org/0.1146/annurev.ecolsys.39.110707.173414

784 Excoffier, L., \& Lischer, H. E. L. (2010). Arlequin suite ver 3.5: A new series of programs to 785 perform population genetics analyses under Linux and Windows. Molecular Ecology Resources, 10, 564-567.

Excoffier, L., \& Ray, N. (2008). Surfing during population expansions promotes genetic 788 revolutions and structuration. Trends in Ecology and Evolution, 23, 347-351. 
Forester, B., Lasky, J., Wagner, H., Urban, D. (2018). Comparing methods for detecting multilocus adaptation with multivariate genotype-environment associations. Molecular Ecology, 27, 2215-2233.

793 Galindo, H., Olson, D., \& Palumbi, S. (2006). Seascape genetics: A coupled oceanographicgenetic model predicts population structure of Caribbean corals. Current Biology, 16, 1622-1626. https://doi.org/10.1016/j.cub.2006.06.052

796 Gautier, M. (2015). Genome-wide scan for adaptive divergence and association with 797 population-specific covariates. Genetics, 201, 1555-1579.

798 Gilbert, K., \& Whitlock, M. (2017). The genetics of adaptation to discrete heterogeneous environments: frequent mutation or large-effect alleles can allow range expansion. Journal of Evolutionary Biology, 30, 591-602. https://doi.org/10.1111/jeb.13029

801 Goodsman, D., Cooke, B., Coltman, D., \& Lewis, M. (2014). The genetic signature of rapid 802 range expansions: how dispersal, growth and invasion speed impact heterozygosity and allele surfing. Theoretical Population Biology, 98, 1-10. https://doi.org/10.1016/j.tpb.2014.08.005

805 Grosholz, E., Ashton, G., Bradley, M., Brown, C., Ceballos-Osuna, L., Chang, A., ... Tepolt, 806 C. (2021). Stage-specific overcompensation, the Hydra effect, and the failure to eradicate an invasive predator. Proceedings of the National Academy of Science U.S.A., 118, e2003955118. https://doi.org/10.1073/pnas.2003955118

809 Hampton, S., \& Griffiths, C. (2007). Why Carcinus maenas cannot get a grip on South Africa's $810 \quad$ wave-exposed coastline. African Journal of Marine Science, 29, 123-126. https://doi.org/10.2989/AJMS.2007.29.1.11.76

812 Hart, A., Ginzburg, S., Xu, M., Fisher, C. R., Rahmatpour, N., Mitton, J. B., ... Wegrzyn, J. L. 813 (2020). EnTAP: Bringing faster and smarter functional annotation to non-model eukaryotic transcriptomes. Molecular Ecology Resources, 20, 591-604.

815 Hedgecock, D. (1986). Is gene flow from pelagic larval dispersal important in the adaptation 816 and evolution of marine invertebrates? Bulletin of Marine Science, 39, 550-564. 
817 Hidalgo, F., Barón, P., \& Orensanz, J. (2005). A prediction come true: the green crab invades 818 the Patagonian coast. Biolical Invasions, 7, 547-552. https://doi.org/10.1007/s10530819 004-5452-3

820 Huang, K., Andrew, R. L., Owens, G. L., Ostevik, K. L., \& Rieseberg, L. H. (2020). Multiple 821 chromosomal inversions contribute to adaptive divergence of a dune sunflower ecotype. 822 Molecular Ecology, 29, 2535-2549. https://doi.org/10.1111/mec.15428

823 Kapun, M., Fabian, D., Goudet, J., \& Flatt, T. (2016). Genomic evidence for adaptive 824 inversion clines in Drosophila melanogaster. Molecular Biology \& Evolution, 33, 1317825 1336. https://doi.org/10.1093/molbev/msw016

826 Kawecki, T., Ebert, D. (2004). Conceptual issues in local adaptation. Ecology Letters, 7 , 827 1225-1241. https://doi.org/10.1111/j.1461-0248.2004.00684.x

828 Kemppainen, P., Knight, C. G., Sarma, D. K., Hlaing, T., Prakash, A., Maung Maung, Y. N., ... 829 Walton, C. (2015). Linkage disequilibrium network analysis (LDna) gives a global view of 830 chromosomal inversions, local adaptation and geographic structure. Molecular Ecology 831 Resources, 15, 1031-1045. https://doi.org/10.1111/1755-0998.12369

832 Ketola, T., Mikonranta, L., Zhang, J., Saarinen, K., Örmälä, A. M., Friman, V., ... Laakso, J. 833 (2013). Fluctuating temperature leads to evolution of thermal generalism and 834 preadaptation to novel environments. Evolution, 67, 2936-2944.

835 https://doi.org/10.1111/evo.12148

836 Kilkenny, F., \& Galloway, L. (2012). Adaptive divergence at the margin of an invaded range. 837 Evolution, 67, 722-731. https://doi.org/10.5061/dryad.6b2t6

838 Kinlan, B., \& Gaines, S. (2003). Propagule dispersal in marine and terrestrial environments: a 839 community perspective. Ecology, 84, 2007-2020. https://doi.org/10.1890/01-0622

840 Kirkpatrick, M. (2010). How and why chromosome inversions evolve. PloS Biology, 8, 841 e1000501. https://doi.org/10.1371/journal.pbio.1000501

842 Kirubakaran, T. G., Grove, H., Kent, M. P., Sandve, S. R., Baranski, M., Nome, T., .. 843 Andersen, $\varnothing$. (2016). Two adjacent inversions maintain genomic differentiation between 844 migratory and stationary ecotypes of Atlantic cod. Molecular Ecology, 25, 2130-2143.

This article is protected by copyright. All rights reserved 
846 Koehn, R., Newell, R., \& Immermann, F. (1980). Maintenance of an aminopeptidase allele 847 frequency cline by natural selection. Proceedings of the National Academy of Sciences U.S.A., 77, 5385-5389. https://doi.org/10.1073/pnas.77.9.5385

849 Kohn, M., Murphy, W., Ostrander, E., \& Wayne, R. (2006). Genomics and conservation genetics. Trends in Ecology and Evolution, 21, 629-637. https://doi.org/10.1016/j.tree.2006.08.001

852 Lamichhaney, S., \& Andersson, L. (2019). A comparison of the association between large 853 haplotype blocks under selection and the presence/absence of inversions. Ecology and Evolution, 9, 4888-4896. https://doi.org/10.1002/ece3.5094

855 Langmead, B., \& Salzberg, S. (2013). Fast gapped-read alignment with Bowtie 2. Nature 856 Methods, 9, 357-359.

857 Lee, C., \& Gelembiuk, G. (2008). Evolutionary origins of invasive populations. Evolutionary 858 Applications, 1, 427-448. https://doi.org/10.1111/j.1752-4571.2008.00039.x

859 Lee, C., Kiergaard, M., Gelembiuk, G., Eads, B., \& Posavi, M. (2011). Pumping ions: Rapid 860 parallel evolution of ionic regulation following habitat invasions. Evolution, 65, 2229$861 \quad$ 2244. https://doi.org/10.1111/j.1558-5646.2011.01308.x

862 Llaurens, V., Whibley, A., \& Joron, M. (2017). Genetic architecture and balancing selection: 863 the life and death of differentiated variants. Molecular Ecology, 26, 2430-2448.

864 https://doi.org/10.1111/mec.14051

865 Lotterhos, K. E., \& Whitlock, M. C. (2014). Evaluation of demographic history and neutral 866 parameterization on the performance of $\mathrm{F}_{\mathrm{ST}}$ outlier tests. Molecular Ecology, 23, 2178867 2192. https://doi.org/10.1111/mec.12725

868 Martin, M. (2011). Cutadapt removes adapter sequences from high-throughput sequencing 869 reads. EMBnet Journal, 17, 10-12.

870 McKenna, A., Hanna, M., Banks, E., Sivachenko, A., Cibulskis, K., Kernytsky, A., ... DePristo, M. A. (2010) The Genome Analysis Toolkit: a MapReduce framework for analyzing nextgeneration DNA sequencing data. Genome Resources, 20, 1297-1303. 
Min, X. J., Butler, G., Storms, R., \& Tsang, A. (2005). OrfPredictor: predicting protein-coding regions in EST-derived sequences. Nucleic Acids Research, 33, W677-W680.

Munday, P., Warner, R., Monro, K., Pandolfi, J., \& Marshall, D. (2013). Predicting evolutionary responses to climate change in the sea. Ecology Letters, 16, 1488-1500. https://doi.org/10.1111/ele.12185

Oksanen, J., Blanchet, F. G., Friendly, M., Kindt, R., Legendre, P., McGlinn, D., ... Wagner, H. vegan: Community Ecology Package (R package version 2.4-3. https://CRAN.Rproject.or). R package version 2.4-3. https://CRAN.R-project.org.

Palumbi, S., \& Pinsky, M. (2014). Marine dispersal, ecology, and conservation. In M. Bertness, J. Bruno, B. Silliman, \& J. Stachowicz (Eds.), Marine Community Ecology and Conservation (1st ed., pp. 57-84). Sunderland, MA, USA: Sinauer Associates.

Patro, R., Duggal, G., Love, M. I., Irizarry, R. A., \& Kingsford, C. (2017). Salmon provides fast and bias-aware quantification of transcript expression. Nature Methods, 14, 417-419.

Pembleton, L. W., Cogan, N. O. I., \& Forster, J. W. (2013). StAMPP: An R package for calculation of genetic differentiation and structure of mixed-ploidy level populations. Molecular Ecology Resources, 13, 946-952.

Pespeni, M., \& Palumbi, S. (2013). Signals of selection in outlier loci in a widely dispersing species across an environmental mosaic. Molecular Ecology, 22, 3580-3597. https://doi.org/10.1111/mec.12337

Phillips, B., Brown, G., Webb, J., \& Shine, R. (2006). Invasion and the evolution of speed in toads. Nature, 439, 803-803. https://doi.org/10.1038/439803a

Price, A., Patterson, N. J., Plenge, R. M., Weinblatt, M. E., Shadick, N. A., \& Reich, D. (2006). Principal components analysis corrects for stratification in genome-wide association studies. Nature Genetics, 38, 904-909.

97 Prunier, J., Dubut, V., Chikhi, L., \& Blanchet, S. (2017). Contribution of spatial heterogeneity 898 in effective population sizes to the variance in pairwise measures of genetic differentiation. Methods in Ecology and Evolution, 8, 1866-1877. https://doi.org/10.1111/2041-210X.12820 
901 R Core Team. R: A Language and Environment for Statistical Computing. Retrieved from 902 https://www.r-project.org

903 Reed, D., \& Frankham, R. (2003). Correlation between fitness and genetic diversity.

904 Conservation Biology, 17, 230-237. https://doi.org/10.1046/j.1523-1739.2003.01236.x

905 Reynolds, R. W., Smith, T. M., Liu, C., Chelton, D. B., Casey, K. S., \& Schlax, M. G. (2007). 906 Daily high-resolution-blended analyses for sea surface temperature. Journal of Climate, 907 20, 5473-5496.

908 Ritter, J. (1970). A summary of preliminary studies of sedimentation and hydrology in Bolinas $909 \quad$ Lagoon, Marin County, California. U.S. Geological Survey, Circular 627.

910 Rius, M., \& Darling, J. (2014). How important is intraspecific genetic admixture to the success 911 of colonising populations? Trends in Ecology and Evolution, 29, 233-242.

912 https://doi.org/10.1016/j.tree.2014.02.003

913 Roman, J., \& Darling, J. (2007). Paradox lost: genetic diversity and the success of aquatic 914 invasions. Trends in Ecology and Evolution, 22, 454-464.

915 https://doi.org/10.1016/j.tree.2007.07.002

916 Rousset, F. (2008). genepop'007: a complete re-implementation of the genepop software for 917 Windows and Linux. Molecular Ecology Resources, 8, 103-106.

918 Sanford, E., \& Kelly, M. (2011). Local adaptation in marine invertebrates. Annual Review of 919 Marine Science, 3, 509-535. https://doi.org/10.1146/annurev-marine-120709-142756 920 Schmidt, P., Bertness, M., \& Rand, D. (2000). Environmental heterogeneity and balancing 921 selection in the acorn barnacle, Semibalanus balanoides. Philosophical Transactions of 922 the Royal Society B, 267, 379-384. https://doi.org/10.1111/j.0014-3820.2001.tb00656.x 923 Schmidt, P. S., \& Rand, D. M. (2001). Adaptive maintenance of genetic polymorphism in an 924 intertidal barnacle: Habitat- and life-stage-specific survivorship of Mpi genotypes.

925 Evolution, 55, 1336-1344. https://doi.org/10.1111/j.0014-3820.2001.tb00656.x 926 See, K. \& Feist, B. (2010). Reconstructing the range expansion and subsequent invasion of 927 introduced European green crab along the west coast of the United States. Biological 928 Invasions, 12, 1305-1318. https://doi.org/10.1007/s10530-009-9548-7

This article is protected by copyright. All rights reserved 
929 Sexton, J., Strauss, S., \& Rice, K. (2011). Gene flow increases fitness at the warm edge of a 930 species' range. Proceedings of the National Academy of Sciences U.S.A., 108, 11704 931 11709. https://doi.org/10.1073/pnas.1100404108

932 Simms, D., Cizdziel, P., \& Chomczynski, P. (1993). TRIzol: a new reagent for optimal single933 step isolation of RNA. Focus, 99-102. https://doi.org/http://dx.doi.org/10.1016/0003934 2670(61)80041-X

935 Slatkin, M. (2008). Linkage disequilibrium-understanding the evolutionary past and mapping 936 the medical future. Nature Reviews Genetics, 9, 477-485.

937 https://doi.org/10.1038/nrg2361

938 Sotka, E. (2012). Natural selection, larval dispersal, and the geography of phenotype in the 939 sea. Integrative and Comparative Biology, 52, 538-545.

940 https://doi.org/10.1093/icb/ics084

941 Sundqvist, L., Keenan, K., Zackrisson, M., Prodöhl, P., \& Kleinhans, D. (2016). Directional 942 genetic differentiation and asymmetric migration. Ecology \& Evolution, 6, 3461-3475.

943 Szpiech, Z. A., Jakobsson, M., \& Rosenberg, N. A. (2008). ADZE: a rarefaction approach for 944 counting alleles private to combinations of populations. Bioinformatics, 24, 2498-2504.

945 Szücs, M., Vahsen, M. L., Melbourne, B. A., Hoover, C., Weiss-Lehman, C., \& Hufbauer, R. 946 A. (2017). Rapid adaptive evolution in novel environments acts as an architect of 947 population range expansion. Proceedings of the National Academy of Sciences U.S.A., $948 \quad 114,13501-13506$. https://doi.org/10.1073/pnas.1712934114

949 Takahashi, Y., Suyama, Y., Matsuki, Y., Funayama, R., Nakayama, K., \& Kawata, M. (2016). 950 Lack of genetic variation prevents adaptation at the geographic range margin in a 951 damselfly. Molecular Ecology, 25, 4450-4460. https://doi.org/10.1111/mec.13782

952 Tepolt, C., Darling, J. A., Bagley, M. J., Geller, J. B., Blum, M. J., \& Grosholz, E. D. (2009). 953 European green crabs (Carcinus maenas) in the Northeastern Pacific: genetic evidence 954 for high population connectivity and current-mediated expansion from a single introduced 955 956 source population. Diversity and Distributions, 15, 997-1009. https://doi.org/10.1111/j.1472-4642.2009.00605.x

This article is protected by copyright. All rights reserved 
957 Tepolt, C., \& Palumbi, S. (2015). Transcriptome sequencing reveals both neutral and adaptive 958 genome dynamics in a marine invader. Molecular Ecology, 24, 4145-4158.

959 https://doi.org/10.1111/mec.13294

960 Tepolt, C., \& Palumbi, S. (2020). Rapid adaptation to temperature via a potential genomic 961 island of divergence in the invasive green crab, Carcinus maenas. Frontiers in Ecology 962 and Evolution, 8, 580701. https://doi.org/10.3389/fevo.2020.580701

963 Tepolt, C., \& Somero, G. (2014). Master of all trades: thermal acclimation and adaptation of 964 cardiac function in a broadly distributed marine invasive species, the European green 965 crab, Carcinus maenas. Journal of Experimental Biology, 217, 1129-1138.

966 https://doi.org/10.1242/jeb.093849

967 Thia, J., McGuigan, K., Liggins, L., Figueira, W. F., Bird, C. E., Mather, A., ... Riginos, C. 968 (2021). Genetic and phenotypic variation exhibit both predictable and stochastic patterns 969 across an intertidal fish metapopulation. Molecular Ecology, In press.

$970 \quad$ https://doi.org/s0740-5472(96)90021-5

971 Thompson, M. J., \& Jiggins, C. D. (2014). Supergenes and their role in evolution. Heredity, 972 113, 1-8. https://doi.org/10.1038/hdy.2014.20

973 Tigano, A., \& Friesen, V. (2016). Genomics of local adaptation with gene flow. Molecular 974 Ecology, 25, 2144-2164. https://doi.org/10.1111/mec.13606

975 Twyford, A. D., \& Friedman, J. (2015). Adaptive divergence in the monkey flower Mimulus 976 guttatus is maintained by a chromosomal inversion. Evolution, 69, 1476-1486.

$977 \quad$ https://doi.org/10.5061/dryad.5h032.

978 Véliz, D., Duchesne, P., Bourget, E., \& Bernatchez, L. (2006). Stable genetic polymorphism in 979 heterogeneous environments: Balance between asymmetrical dispersal and selection in 980 the acorn barnacle. Journal of Evolutionary Biology, 19, 589-599.

$981 \quad$ https://doi.org/10.1111/j.1420-9101.2005.01000.x

982 Vucetich, J., Waite, T., \& Nunney, L. (1997). Fluctuating population size and the ratio of 983 effective to census population size. Evolution, 51, 2017-2021.

984 Weir, B. S., \& Cockerham, C. C. (1984). Estimating F-statistics for the analysis of population

This article is protected by copyright. All rights reserved 
structure. Evolution, 38, 1358-1370.

986 Welch, W. (1968). Changes in abundance of the green crab, Carcinus maenas (L .), in relation to recent temperature changes. Fishery Bulletin, 67, 337-345.

988 Westram, A., Rafajlović, M., Chaube, P., Faria, R., Larsson, T., Panova, M., ... Butlin, R.

989 (2018). Clines on the seashore: the genomic architecture underlying rapid divergence in 990 the face of gene flow. Evolution Letters, 2-4, 297-309. https://doi.org/10.1002/evl3.74

991 White, C., Selkoe, K. A., Watson, J., Siegel, D. A., Zacherl, D. C., \& Toonen, R. J. (2010). 992 Ocean currents help explain population genetic structure. Proceedings of the Royal 993 Society $B, 277,1685-1694$. https://doi.org/10.1098/rspb.2009.2214

994 White, T., Perkins, S., Heckel, G., \& Searle, J. (2013). Adaptive evolution during an ongoing 995 range expansion: the invasive bank vole (Myodes glareolus) in Ireland. Molecular 996 Ecology, 22, 2971-2985. https://doi.org/10.1111/mec.12343

997 Wickham, H. (2016). ggplot2: Elegant Graphics for Data Analysis. Retrieved from $998 \quad$ http://ggplot2.org

999 Wilson, J., Dormontt, E., Prentis, P., Lowe, A., \& Richardson, D. (2009). Something in the way 1000 you move: dispersal pathways affect invasion success. Trends in Ecology and Evolution, $100124,136-144$. https://doi.org/10.1016/j.tree.2008.10.007

1002 Xuereb, A., Benestan, L., Normandeau, É., Daigle, R. M., Curtis, J. M. R., Bernatchez, L., \& 1003 Fortin, M. J. (2018). Asymmetric oceanographic processes mediate connectivity and 1004 population genetic structure, as revealed by RADseq, in a highly dispersive marine 1005 invertebrate (Parastichopus californicus). Molecular Ecology, 27, 2347-2364.

1006 https://doi.org/10.1111/mec.14589

1007

\section{Data Accessibility}

1009 Raw transcriptome reads from new sequencing for this project have been deposited in 1010 GenBank's Sequence Read Archive (SRA) under BioProject ID PRJNA690934 and 1011 BioSample IDs SAMN17267686-SAMN17267781. The cleaned transcriptome, high-quality 1012 individual SNP genotypes, and custom scripts used in this bioinformatics pipeline from in this 
1013 paper will be archived in Dryad upon acceptance. Raw sequence reads from 2011,

1014 reanalyzed in this project, are available in the SRA under BioProject ID PRJNA283611 and 1015 BioSample IDs SAMN03653390-SAMN03653413.

1016

\section{Author Contributions}

1018 All authors designed the research. CT performed research, analyzed data, and wrote the 1019 paper. All authors edited multiple drafts.

This article is protected by copyright. All rights reserved 


\section{Tables}

Table 1: Sampling information and summary statistics for each site $\mathrm{x}$ year sample. Adult $=1+$ year old animal; YOY = Young of the Year or $<1$ year old animal. Noly = number of polymorphic SNPs; Ar = allelic richness; $\mathrm{pAr}=$ private allelic richness; $H_{O}=$ observed heterozygosity; $H_{E}=$ expected heterozygosity; $F_{I S}=$ Wright's inbreeding coefficient. All samples showed a significant heterozygote excess $(p<0.05)$.

\begin{tabular}{|l|c|c|c|c|c|c|c|c|c|c|c|c|}
\hline Code & Site & Coordinates & Year & Age & $\mathbf{N}$ & Npoly & Ar & pAr & $\boldsymbol{H}_{\boldsymbol{O}}$ & $\boldsymbol{H}_{\boldsymbol{E}}$ & $\boldsymbol{F}$ IS \\
\hline ES_15* & Elkhorn Slough, CA & $36.820,-121.745$ & 2015 & Adult & 12 & 5,546 & 1.708 & 0.00697 & 0.2612 & 0.2510 & -0.0409 \\
SF_15* & San Francisco Bay, CA & $37.997,-122.370$ & 2015 & Adult & 12 & 5,549 & 1.702 & 0.00621 & 0.2510 & 0.2491 & -0.0078 \\
SF_16 & San Francisco Bay, CA & $37.997,-122.370$ & 2016 & YOY & 12 & 5,560 & 1.705 & 0.00666 & 0.2593 & 0.2501 & -0.0365 \\
SL_11 & Seadrift Lagoon, CA & $37.907,-122.662$ & 2011 & Adult & 12 & 5,233 & 1.669 & 0.00494 & 0.2461 & 0.2414 & -0.0196 \\
SL_15* & Seadrift Lagoon, CA & $37.907,-122.662$ & 2015 & YOY & 12 & 5,234 & 1.675 & 0.00584 & 0.2609 & 0.2424 & -0.0761 \\
SL_16 & Seadrift Lagoon, CA & $37.907,-122.662$ & 2016 & YOY & 12 & 5,264 & 1.677 & 0.00434 & 0.2498 & 0.2442 & -0.0228 \\
BB_15* & Bodega Bay, CA & $38.324,-123.054$ & 2015 & Adult & 12 & 5,538 & 1.706 & 0.00645 & 0.2681 & 0.2511 & -0.0674 \\
OR_16* & Tillamook Bay, OR & $45.542,-123.904$ & 2016 & YOY & 12 & 5,548 & 1.711 & 0.00762 & 0.2618 & 0.2539 & -0.0311 \\
BC_11 & Barkley Sound, BC & $49.026,-125.346$ & 2011 & Adult & 12 & 5,562 & 1.711 & 0.00771 & 0.2600 & 0.2520 & -0.0316 \\
BC_16* & Barkley Sound, BC & $49.026,-125.346$ & 2016 & Adult & 12 & 5,517 & 1.705 & 0.00676 & 0.2630 & 0.2512 & -0.0471 \\
\hline
\end{tabular}

* indicates samples used in tests of selection and relative migration. 


\section{Figures}

Figure 1: Map of sampling sites; year(s) of sampling given in italics under site names. From north to south: Barkley Sound, BC $(2011,2016)$; Tillamook Bay, OR (2016); Bodega Bay, CA (2015); Seadrift Lagoon, CA (2011, 2015, 2016); San Francisco Bay, CA $(2015,2016)$; and Elkhorn Slough, CA (2015). Asterisk indicates the location where the species was initially introduced (first detected in 1989).

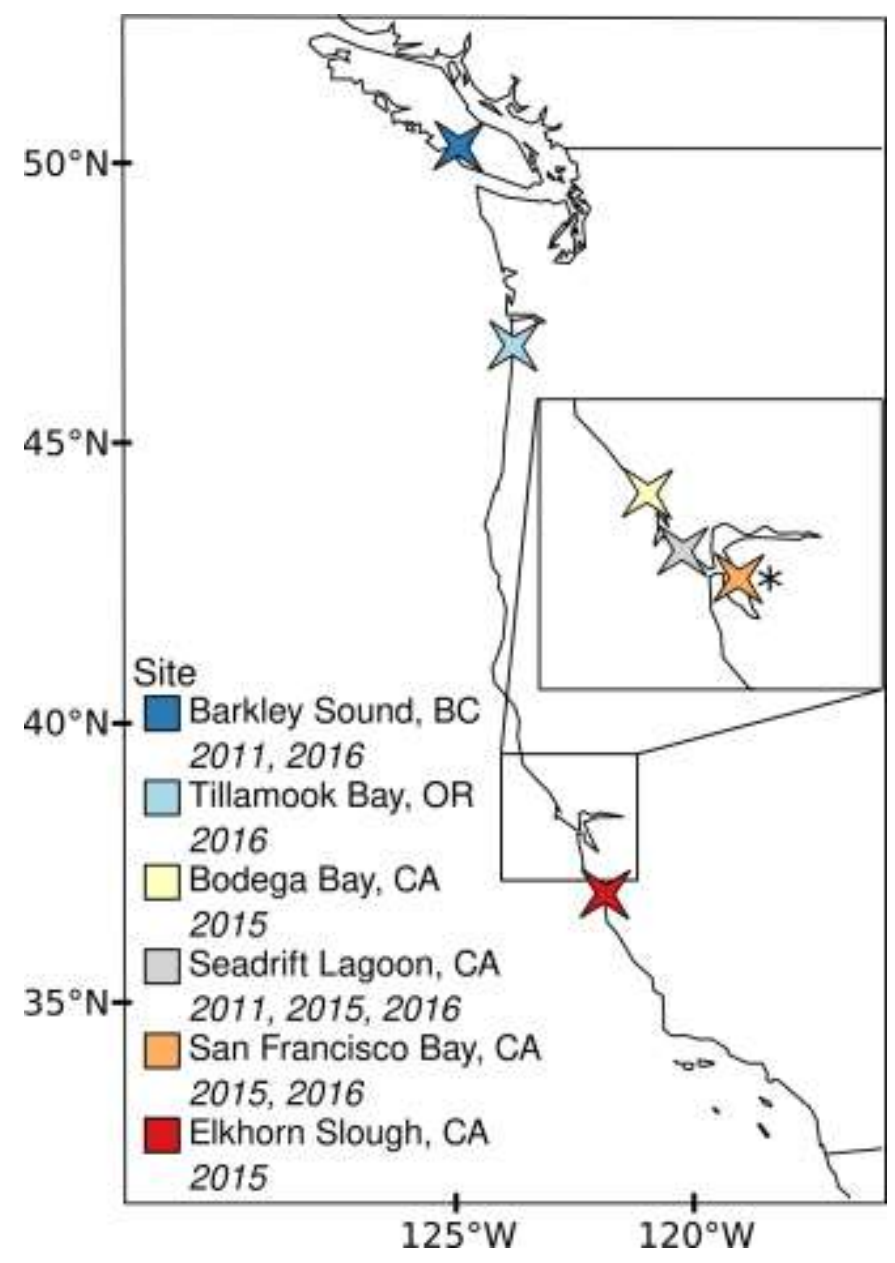


Figure 2: Linkage disequilibrium analysis of the full 9,376 SNP set, showing evidence for an inferred inversion. A-B: Clustering in LDna network analysis showing nested single and compound outlier LD clusters. In $B$, the inferred inversion (compound cluster in $A$ ) is indicated by an arrow and highlighted in red. C: PCA of 168 SNPs in inferred inversion. D: FIs of 168 SNPs in inferred inversion, grouped by PC1 position in C. E: PCA of the full 9,376 SNP set. F: PCA of the full 9,376 SNP set excluding the 168 SNPs in the inferred inversion. For C-F, four individuals were excluded because they were missing high-quality genotypes at $>20 \%$ of SNPs in the inferred inversion.

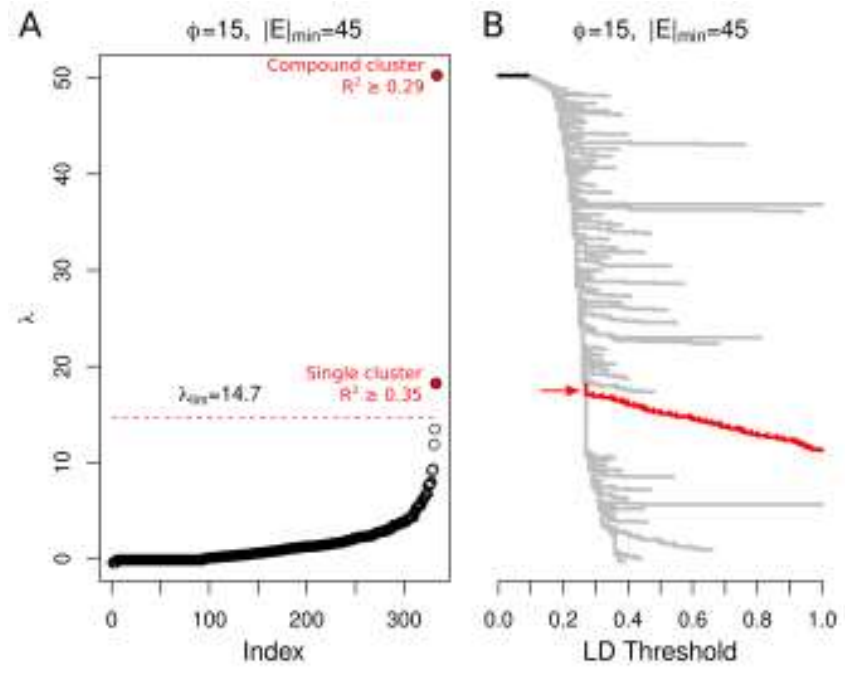

D

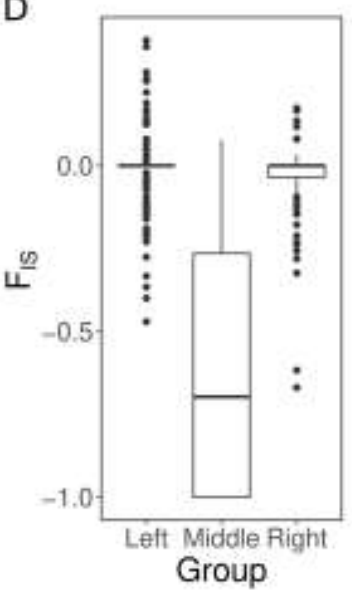

$E$

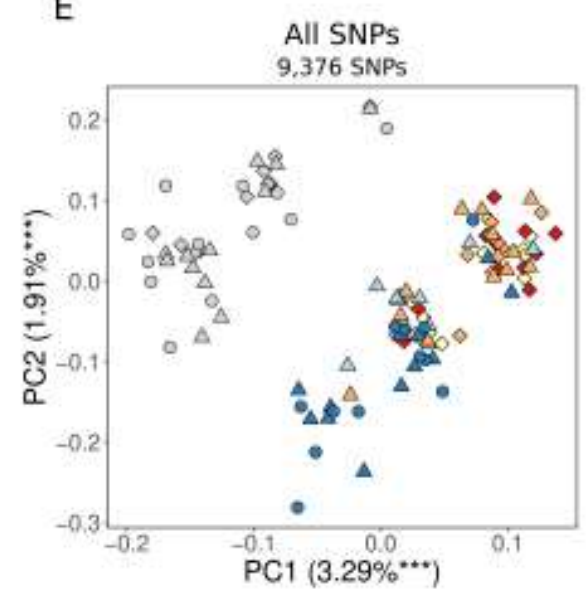

C Inferred inversion 168 SNPS

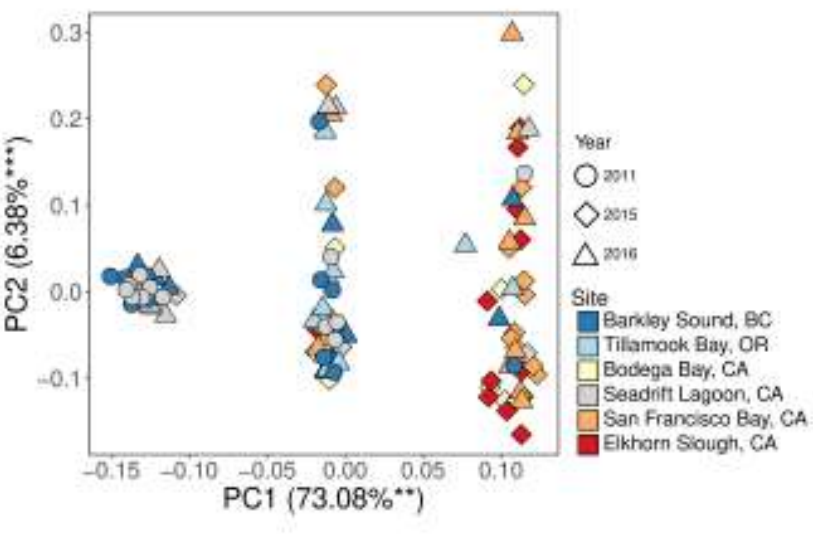

$\mathrm{F}$

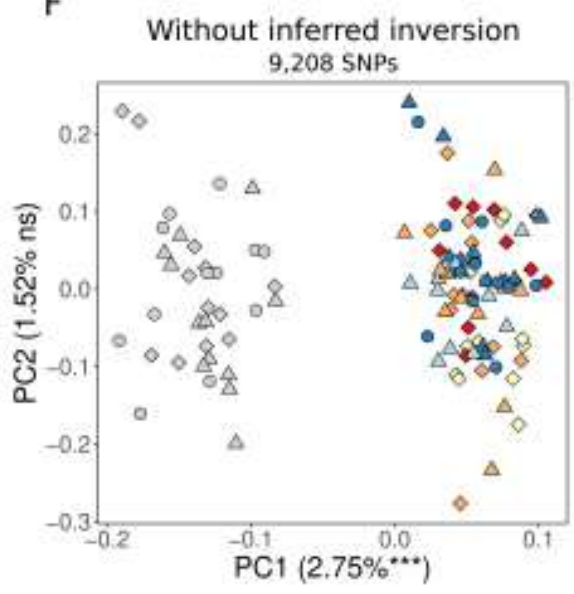


Figure 3: Genetic structure, diversity, and migration across all sites, showing high gene flow among all sites except Seadrift Lagoon. A: PCA of the independent 6,848 SNPs. B: PCA of the putatively neutral 6,311 SNPs. C: Allelic richness by population and collection year across the 6,848 independent SNPs, plotted against distance from the initial point of introduction in San Francisco Bay, CA. Points from the same site have been jittered horizontally for clarity. Vertical bars indicate standard error. Starred samples have significantly lower allelic richness than non-starred samples. D: Relative migration between sites, calculated with the $\mathrm{Nm}$ method, across the 6,662 independent SNPs in the five "open" sites. The highest observed rate is set to 1 , and all other rates are scaled to that maximum; estimated migration both into and out of Seadrift was lower than migration between all other sites.
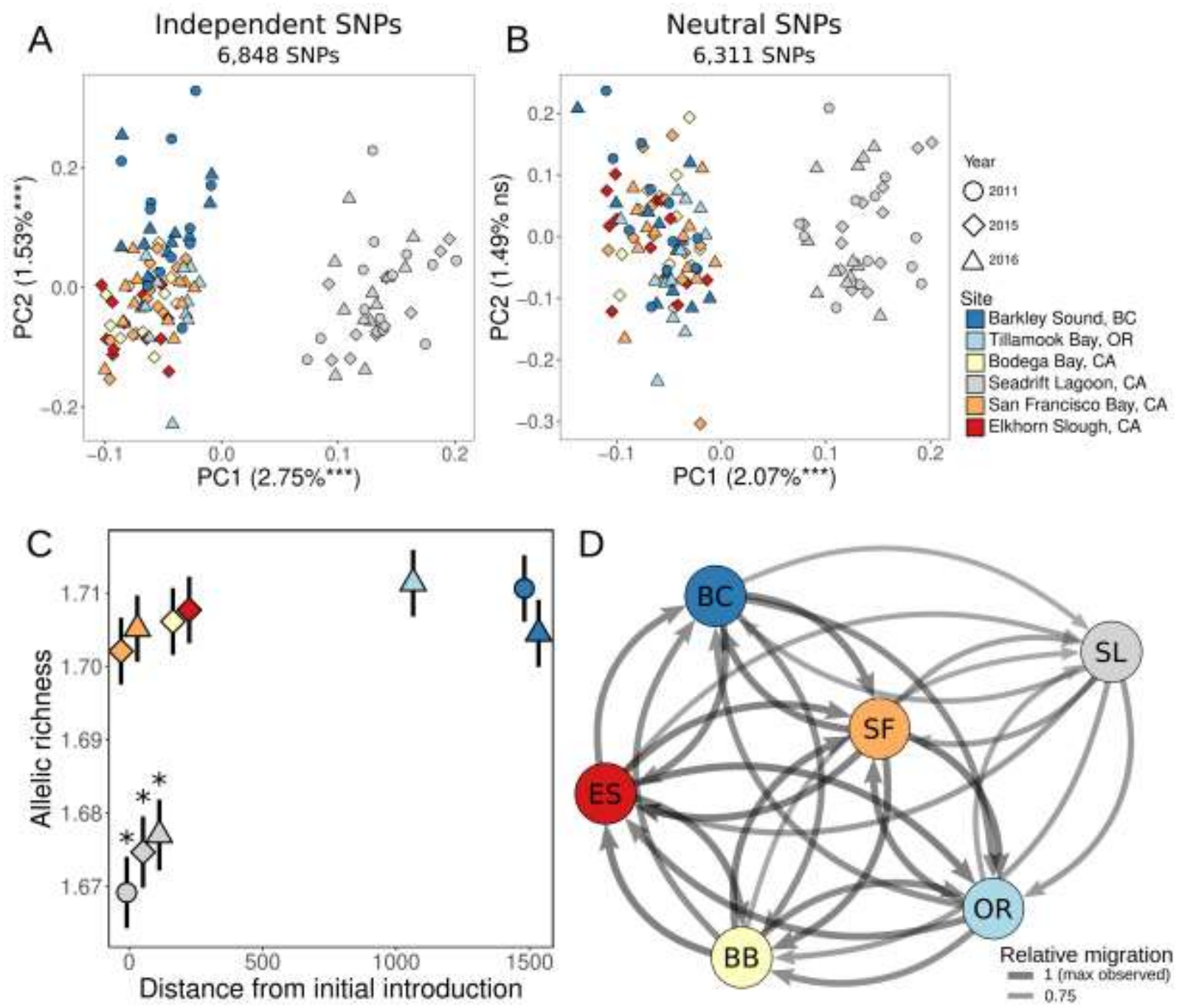
Figure 4: Comparison of isolation-by-distance (IBD) patterns across all open populations (excluding Seadrift Lagoon), showing IBD driven by SNPs in the inferred inversion. A: For all 6,848 independent SNPs (red); 6,794 independent SNPs excluding the large outlier LD cluster (gray); and 6,311 putatively neutral independent SNPs (black). B: For all 144 frequency outlier SNPs across the open populations (aqua); and all 54 SNPs from the inferred inversion in the independent SNP set (blue). The relationships in A are shown in B with smaller points; note the difference in Y-axis magnitude between the two panels.
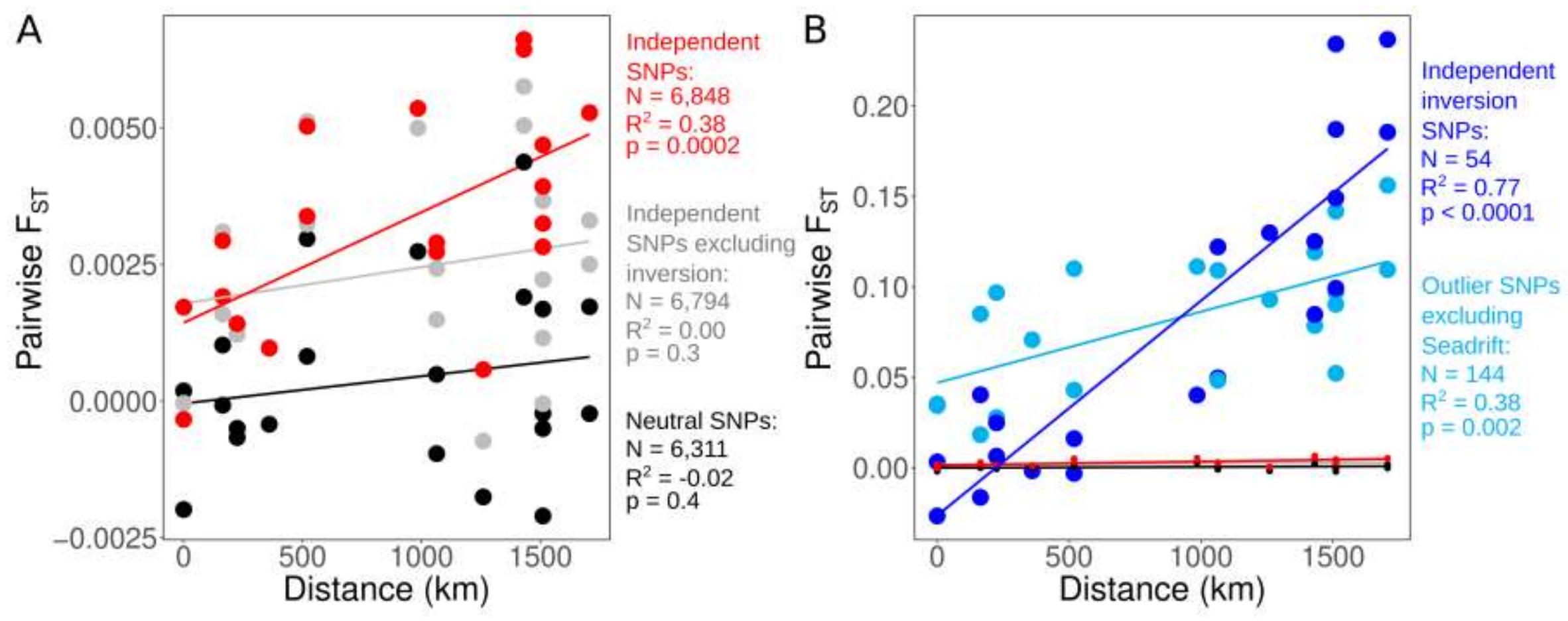
Figure 5: Correlation between Minor Allele Frequency (MAF) and latitude or July SST at candidate genomic regions, showing putative selection to temperature or latitude across the five "open" sites at environmental outlier SNPs. Asterisks indicate the location where the species was initially introduced (first detected in 1989). In both cases, Seadrift Lagoon (gray point) is shown for comparison but was not used in the regression lines or equations. A) The inferred inversion; samples were classed into overall "inversion genotypes" based on their group membership in Figure 2C. B) Outlier SNP in the protein SGT homolog transcript.
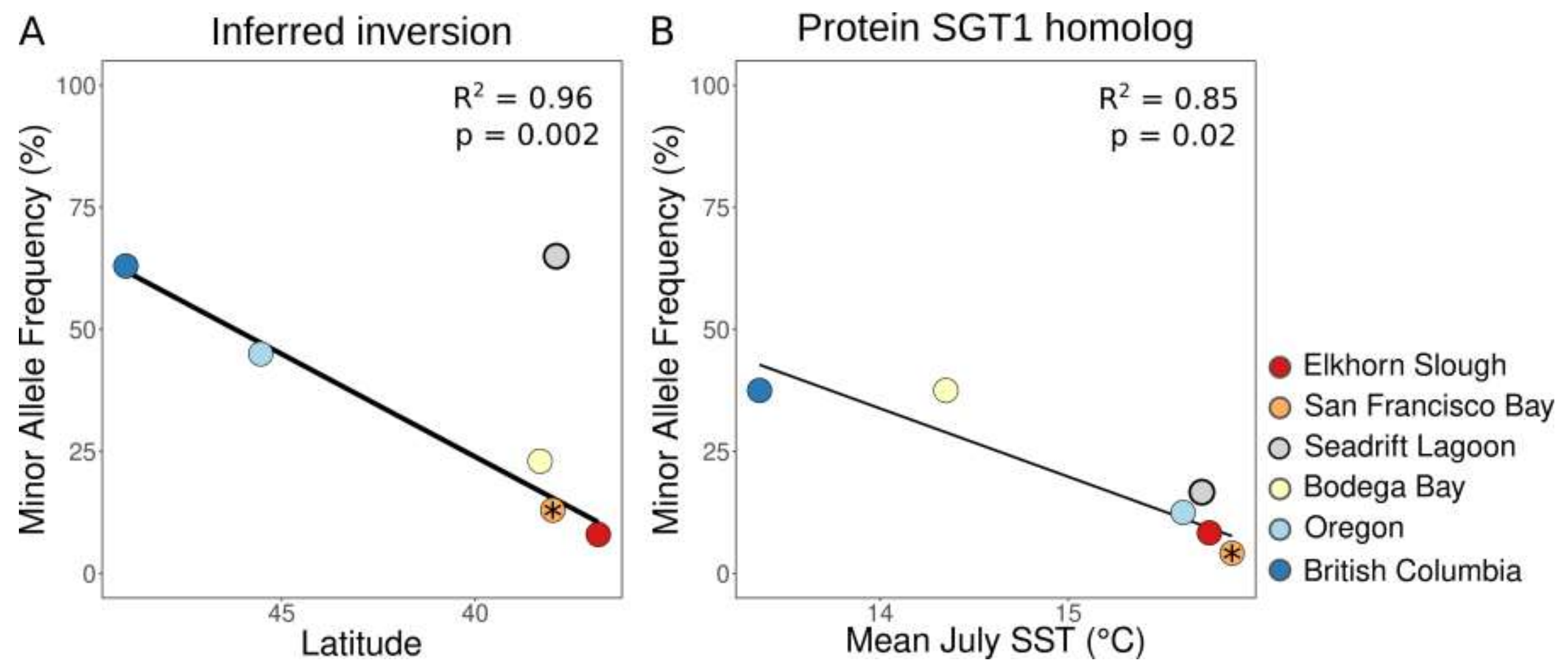